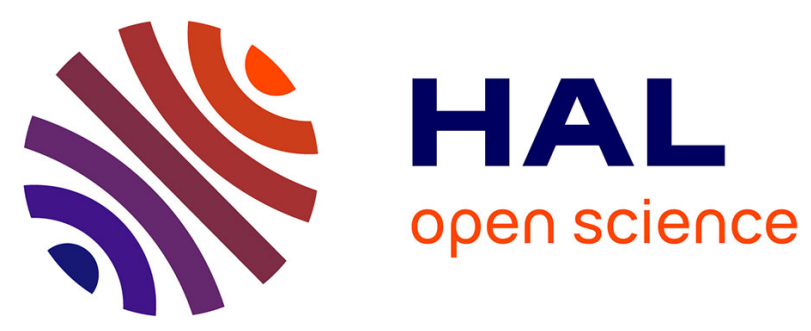

\title{
Estimating local bonding/antibonding character of canonical molecular orbitals from their energy derivatives. The case of coordinating lone pair orbitals
}

Patrick Chaquin, Yves Canac, Christine Lepetit, D Zargarian, Rémi Chauvin

\section{- To cite this version:}

Patrick Chaquin, Yves Canac, Christine Lepetit, D Zargarian, Rémi Chauvin. Estimating local bonding/antibonding character of canonical molecular orbitals from their energy derivatives. The case of coordinating lone pair orbitals. International Journal of Quantum Chemistry, 2016, 116, pp.1285 1295. 10.1002/qua.25174. hal-01383238

\section{HAL Id: hal-01383238 \\ https://hal.science/hal-01383238}

Submitted on 18 Oct 2016

HAL is a multi-disciplinary open access archive for the deposit and dissemination of scientific research documents, whether they are published or not. The documents may come from teaching and research institutions in France or abroad, or from public or private research centers.
L'archive ouverte pluridisciplinaire HAL, est destinée au dépôt et à la diffusion de documents scientifiques de niveau recherche, publiés ou non, émanant des établissements d'enseignement et de recherche français ou étrangers, des laboratoires publics ou privés. 


\section{Estimating Local Bonding/Antibonding Character of \\ Canonical Molecular Orbitals from their Energy \\ Derivatives. The Case of Coordinating Lone Pair Orbitals}

Patrick Chaquin ${ }^{1}$, Yves Canac ${ }^{2}$, Christine Lepetit ${ }^{3}$, Davit Zargarian ${ }^{4}$, Remi Chauvin $^{5}$

Correspondance to Patrick Chaquin (E-mail : chaquin@lct.jussieu.fr)

1. P. Chaquin

Sorbonne Universités, UPMC Univ Paris 06, CNRS UMR 7616, Laboratoire de Chimie

Théorique (LCT), F-75005 Paris, France.

${ }^{2}$ Y. Canac

CNRS, LCC (Laboratoire de Chimie de Coordination), 205, route de Narbonne, BP 44099 , F-31077 Toulouse Cedex 4, France.

Université de Toulouse, UPS, INPT, F-31077 Toulouse Cedex 4, France.

${ }^{3}$ C. Lepetit

CNRS, LCC (Laboratoire de Chimie de Coordination), 205, route de Narbonne, BP 44099, F-31077 Toulouse Cedex 4, France.

Université de Toulouse, UPS, INPT, F-31077 Toulouse Cedex 4, France.

${ }^{4}$ D. Zargarian

Département de chimie, Université de Montréal, Montréal (Québec), Canada H3C 3J7

${ }^{5}$. R. Chauvin

CNRS, LCC (Laboratoire de Chimie de Coordination), 205, route de Narbonne, BP 44099, F-31077 Toulouse Cedex 4, France.

Université de Toulouse, UPS, INPT, F-31077 Toulouse Cedex 4, France. 


\section{ABSTRACT.}

According to Koopmans theorem, the derivative of the energy of a canonical MO with respect to nuclear coordinates quantifies its bonding/antibonding character. This quantity allows predictions of bond length variation upon ionisation in a panel of 19 diatomic species. In polyatomic molecules, the derivative of a MO energy with respect to a given bond length reveals the nature and the degree of the bonding/antibonding contribution of this $\mathrm{MO}$ with respect to this bond. Accordingly, the HOMO "lone pairs" of $\mathrm{CO}$ and $\mathrm{CN}^{-}$and the HOMO-2 of $\mathrm{CH}_{3} \mathrm{CN}$ are found to be antibonding with respect to the $\mathrm{C}-\mathrm{X}$ bond $(\mathrm{X}=\mathrm{N}, \mathrm{O})$, whereas the HOMO of $\mathrm{N}_{2}$ is found to be bonding. With the same approach, the variation of the bonding character in the MOs of $\mathrm{CO}$ and $\mathrm{CH}_{3} \mathrm{CN}$ upon interaction with an electron acceptor (modelled through the approach of a proton) or by applying an electric field was studied.

\section{Introduction}

\section{The bonding/antibonding character of a molecular orbital}

Several essential concepts in chemistry rely on imperfect definitions, especially regarding quantitative aspects (electronegativity, aromaticity, dativity, etc.). This is also the case of the bonding/antibonding character of molecular orbitals (MOs), which can be appraised by several approaches. According to the IUPAC Gold Book ${ }^{[1]}$ "a bonding (resp. antibonding) molecular orbital is a molecular orbital whose occupation by electrons increases (resp. decreases) the total bonding - usually lowers (resp. increases) the total energy of a molecule. Generally, the energy level of a bonding MO lies lower (resp. higher) than the average of the valence orbitals of the atoms constituting the molecule ". This definition corresponds to a global molecular character. The chemist is nevertheless more often interested in a local character with respect to a given bond. In this specific purpose, the IUPAC definition can suggests two criteria.

From a theoretical point of view, a MO can be defined to be bonding between atoms A and B when its energy lies below the energy of the AOs from which it is built (definition i). This definition entails the calculation of an "orbital dissociation energy" by computing the mean energy of the both atomic hybrids involved in the MO. ${ }^{[2]}$ Another possible definition (ii) is based on the bond dissociation energy: a MO is said to be bonding between two nuclei A and B if the presence of an electron in this $\mathrm{MO}$ increases the dissociation energy $\mathrm{D}_{\mathrm{AB}}$. Application of this definition requires that we determine the dissociation energies of both the charge-neutral $\mathrm{AB}$ and the cationic species $\mathrm{AB}^{+}$resulting from the loss of one electron from the $\mathrm{MO}$ in question; in this sense, this approach presents a challenge, theoretically as well as experimentally.

An alternative definition (iii) is based on the force exerted by electrons on nuclei: a MO is considered bonding $^{\mathrm{a}}$ when the force exerted by the corresponding electron density is attractive

\footnotetext{
a A distinction has been established between "binding "which refers to the force and "bonding "which refers to the energy. In the practice, these both concepts are closely related and only the most familiar term of "bonding" will be used hereafter.
} 
and thus tends to shorten the bond length A-B and vice versa. The latter definition will be investigated in the present work. We believe that such an approach is of particular interest for experimentalists because the bonding character of a MO can be correlated to the variation of a number of observable parameters, such as bond length and vibration frequencies, when the corresponding electron is totally (ionization) or partially removed. This is particularly relevant in coordination chemistry where the metal-ligand interaction results in some degree of electron transfer between the ligand and the metal MOs.

Following the Dewar-Chatt-Duncanson model, the bonding in the transition metal complex may be described by the donation from an occupied MO of the ligand to a vacant $\mathrm{MO}$ of the metal and back-bonding from an occupied MO of the metal to an empty orbital of the ligand. ${ }^{[3]}$ Indeed, the overlap of MOs of the metal and ligand of suitable energy and symmetry yields a new set of $\sigma$ or $\pi$ MOs of bonding, non-bonding or antibonding character in the transition metal complex. The $\sigma$ MOs normally involve the above-noted donor-acceptor interaction $(\mathrm{L} \rightarrow \mathrm{M})$, whereas the $\pi$ MOs may involve the same type of interaction or its opposite (namely, $\pi$-back bonding, $\mathrm{M} \rightrightarrows \mathrm{L}$ ). The knowledge of the character of the MOs involved in the metal-ligand interaction (totally or partially bonding/antibonding) may thus allow the rationalization and prediction of the experimental spectroscopic data and/or chemical reactivity of the related complex for which substitution, addition or dissociation, electron transfer reactions, or reaction at coordinated ligands may occur.

\section{Theoretical Basis}

\section{Force concept in chemical bonding.}

Using the Hellmann-Feynman theorem, Berlin ${ }^{[4]}$ showed that, for a wave function solution of the Schrödinger equation, the force exerted on each nucleus by the other nuclei and by the electrons may be derived in terms of classical electrostatics.

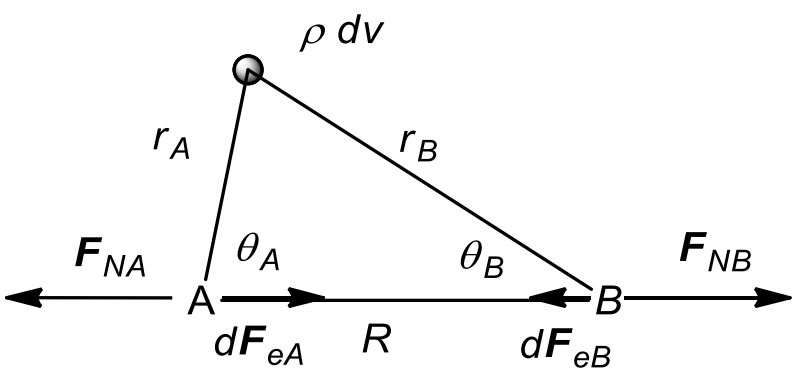

Scheme 1. Electrostatic forces acting in a diatomic molecule AB

In the case of a diatomic molecule $\mathrm{AB}$ of internuclear distance $R$, the force $F_{\mathrm{A}}$ on nucleus $\mathrm{A}$ is the sum of the (repulsive) force $F_{\mathrm{NA}}$ exerted by the other nucleus B (Eq. 1) and the force $F_{\mathrm{eA}}$ exerted by the electrons of total density $\rho(x, y, z)$.

$$
F_{N A}=F_{N B}=\frac{Z_{A} Z_{B}}{R^{2}}
$$


For symmetry reasons, only the projection of the forces on the nuclear axis $\mathrm{AB}$ has to be considered (Scheme 1). The electron force $d F_{e A}$ exerted by the charge $\rho \mathrm{d} v$ on the nucleus $\mathrm{A}$ is attractive (by convention negative) and can be expressed as follows:

$$
d F_{e A}=-\left[\frac{z_{A}}{r_{A}^{2}} \cos \theta_{A}\right] \rho d v
$$

Similarly, $d F_{e b}$ exerted on the nucleus $\mathrm{B}$ is:

$$
d F_{e B}=-\left[\frac{z_{B}}{r_{B}^{2}} \cos \theta_{B}\right] \rho d v
$$

The electron forces $F_{e A}$ and $F_{e B}$ are equal and can be calculated from Eq. 4 involving the electron density $\rho(\mathrm{x}, \mathrm{y}, \mathrm{z})$ and the "Berlin function" $f(x, y, z)$ :

$$
\begin{aligned}
& \quad F_{e A}=F_{e B}=\int d F_{e A}=\int d F_{e B}=-\frac{1}{2} \int\left[\frac{z_{A}}{r_{A}^{2}} \cos \theta_{A}+\frac{z_{B}}{r_{B}^{2}} \cos \theta_{B}\right] \rho d v= \\
& -\frac{1}{2} \int f(x, y, z) \rho(x, y, z) d v
\end{aligned}
$$

The sign of the Berlin function $f(x, y, z)$ indicates therefore the bonding or antibonding contribution of an electron density $\rho$ at the point $x, y, z$ : it is bonding if $f$ is positive or antibonding if $f$ is negative. Thus, for a homonuclear diatomic molecule $\mathrm{A}_{2}$, a bonding zone $(f>$ $0)$ and an antibonding zone $(f<0)$, separated by a non-bonding nodal surface $(f=0)$ can be defined, as illustrated in Figure 1.

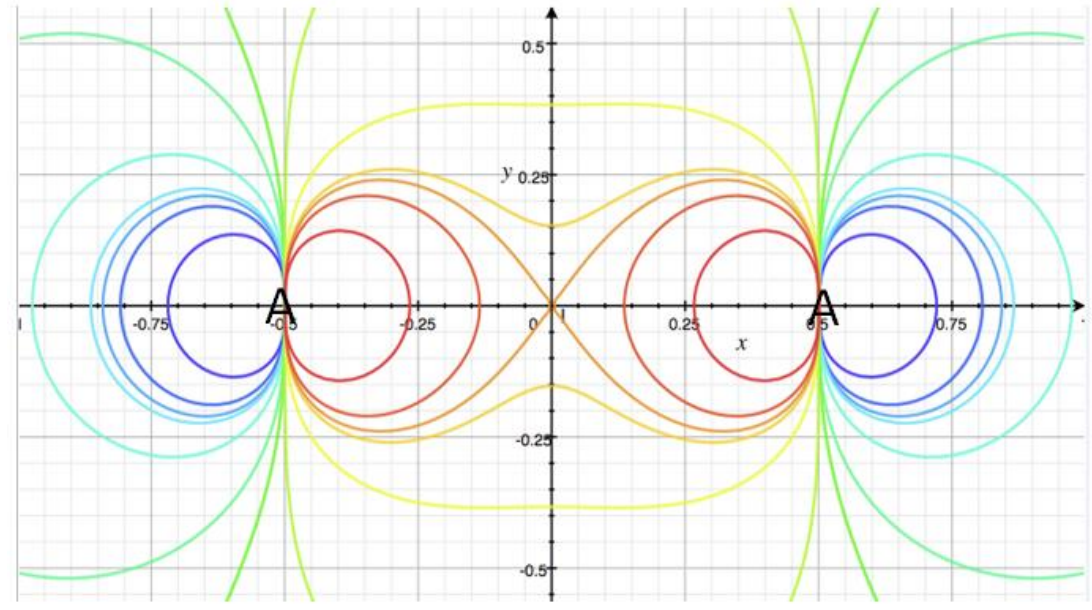

Figure 1. Contour plot of the Berlin function $f(x, y, z)$ for a diatomic molecule $\mathrm{A}_{2}$ (red-yellow: bonding zone $f>0$; green: non-bonding surface $f=0$; blue: antibonding zone $f<0$ ).

For heteronuclear diatomic molecules, the bonding/antibonding zones are reshuffled depending on the ratio $Z_{\mathrm{A}} / Z_{\mathrm{B}}$. Few examples are given in Figure 2 . 


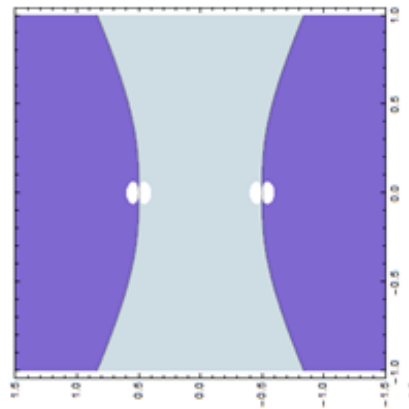

$Z_{A}=Z_{B}$

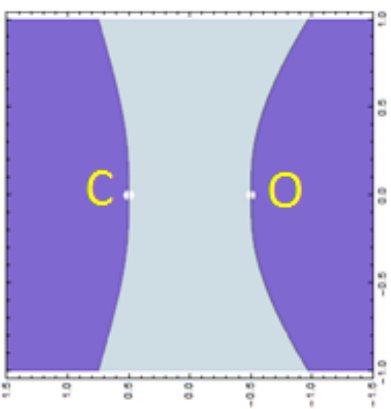

$Z_{A} / Z_{B}=8 / 6$

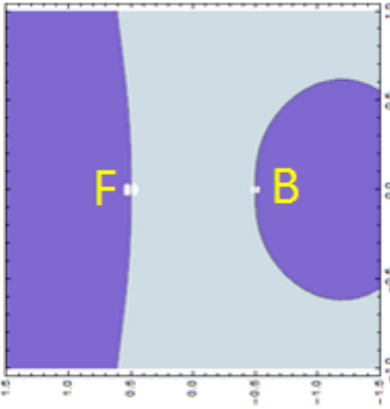

$Z_{A} / Z_{B}=9 / 3$

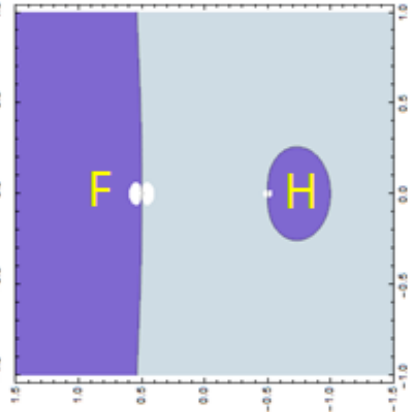

$Z_{A} / Z_{B}=9 / 1$

Figure 2. Bonding $\left(f>0\right.$, light blue) and antibonding $\left(f<0\right.$ dark blue) zones for various $Z_{\mathrm{A}} / \mathrm{Z}_{\mathrm{B}}$ values.

The graphs of Figure 2 are very helpful to understand the origin of the usual "visual" identification of bonding or antibonding MOs, only based on the absence/presence of a nodal element cutting the bond. A bonding MO is mainly located in the internuclear region corresponding to strongly positive values of $f(x, y, z)$. On the other hand, if a nodal surface cuts the $\mathrm{AB}$ segment, the electron density is repelled out of the bonding region and the MO is likely to be antibonding.

\section{MO energy derivative and (anti)bonding character}

From Eq. 1 and Eq. 4, the total force exerted on each nucleus becomes:

$$
F=\frac{z_{A} Z_{B}}{R^{2}}-\frac{1}{2} \int f(x, y, z) \rho d v
$$

Since the total electron density is the sum of occupied spin-orbital densities, the total electronic force can be decomposed into additive orbital forces, following the approach of Bader et al. ${ }^{[5]}$

Tal and Katriel ${ }^{[6]}$ developed an alternative concept of "orbital forces" which is built up from the MO energy derivatives with respect to nuclear coordinates. Let $E^{\circ}$ be the Hartree-Fock (HF) energy of a neutral species and $E_{i}^{+}$the corresponding energy of the cation resulting from the removal of one electron from the $i^{\text {th }}$ spin-orbital $\phi_{\mathrm{i}}$. According to the generalized Koopmans theorem $^{[7]}$, which assumes that the MOs are the same in the cation as in the original neutral species (approximation of frozen orbitals), the energy $\varepsilon_{\mathrm{i}}$ of the $i^{\text {th }}$ spin-orbital is:

$\varepsilon_{i}=E^{0}-E_{i}^{+}$

For a diatomic molecule, the derivative with respect to the internuclear distance $R$ yields:

$$
\frac{d \varepsilon_{i}}{d R}=\frac{d E^{0}}{d R}-\frac{d E_{i}^{+}}{d R}
$$


This indicates that the derivative of the MO energy is the difference of the forces acting on nuclei in the presence/absence of an electron in the MO $\phi_{1}$. If the geometry has been taken at its equilibrium value $R_{\mathrm{e}}$ in the neutral species, $\mathrm{d} E^{0} / \mathrm{d} R=0$ and:

$$
\left(\frac{d \varepsilon_{i}}{d R}\right)_{R=R_{e}}=-\left(\frac{d E_{i}^{+}}{d R}\right)_{R=R_{e}}
$$

According to Eq. 8, if $\varepsilon_{\mathrm{i}}=\mathrm{d} \varepsilon_{\mathrm{i}} / \mathrm{d} R$ is positive, $R$ tends to lengthen upon loss of an electron in order to decrease the ion energy $E^{+}$, which characterizes a bonding $\phi_{\mathrm{i}} \mathrm{MO}$, in agreement with Mulliken's criterion of the "bonding power" of an electron. ${ }^{[8]}$ Contrary to Bader's orbital forces, the sum of $\varepsilon_{\text {i }}$ over occupied MOs is not equal to the total electronic force: it comes from the fact that the total Hartree-Fock energy is not the sum of the occupied orbital energies. However, the $\varepsilon_{\text {i }}$ forces are more closely related to the Mulliken's criterion. Moreover, they have the advantages of being easily computed by a finite difference of a geometrical parameter, for a diatomic molecule as well as a polyatomic one. Indeed, a similar relation is found with the parameter $X$ associated with any geometrical deformation, involving one or several internal parameters (Eq. 9):

$$
\frac{\partial \varepsilon_{i}}{\partial X}=\frac{\partial E^{0}}{\partial X}-\frac{\partial E_{i}^{+}}{\partial X}
$$

Indeed, there is no certainty that, after MO relaxation and once the correlation energy is taken into account, this "Koopmans' orbital force" $\varepsilon_{\text {i }}^{\prime}$ correctly predicts the actual geometrical variation induced by ionization. Nevertheless one can assume that this quantity reflects a trend which indicates, at least, the sign of this variation. At any rate, this assumption should be validated by comparison with experimental results.

From another point of view, considering that bond elongation destabilizes a bonding MO but stabilizes an antibonding $\mathrm{MO}$, this criterion also agrees with the definition (i) (vide supra), provided that the MO energies vary monotonously up to the infinite separation of the atoms, which is generally the case (excluding the cases of endocyclic bonds).

Few works have been devoted to the study of MO energy derivatives in relation to their bonding character. On this basis, Tal and Katriel ${ }^{[6]}$ have determined the bonding character of the MOs of diatomic homonuclear molecules of the Li-F period. Other authors' performed calculations of first and second derivatives of canonical MO energies in some small molecules, ${ }^{[9,10]}$ focussing especially on their geometrical stability ${ }^{[11]}$ (in connection with the Walsh method), or exploring $\sigma$ and $\pi$ stabilization in conjugated systems. ${ }^{[12]}$ The slope of orbital energy under geometrical deformation was also used in relation with photoelectron spectra. ${ }^{[13]}$ Because the Kohn-Sham (KS) MOs used in DFT calculations do not obey the Koopmans theorem and thus do not satisfy eq. 7-8, the derivatives of their energies have not the same physical meaning, as demonstrated by Averill and Painter. ${ }^{[14]}$ These authors nevertheless have shown that these quantities can be also used as a bonding criterion and are in qualitative agreement with their HF analogues in Li-F dimers, though rather different in absolute value. They proposed the denomination of "dynamic orbital force" (DOF) for these derivatives, to differentiate them from the additive "static orbital forces" of Bader. More recently, on the same 
basis (under the designation of "radial orbital energy slopes"), Bickelhaupt et al. performed calculations to determine the bonding character of s-p mixing KS MOs in a set of 6 diatomic molecules. ${ }^{[15]}$ Very recently, finite bond length variations (as "orbital force constants") were used as a measure of the bonding character of KS MOs of few various molecular systems. ${ }^{[16]}$ In what follows, the idea that the bonding/antibonding character of a given canonical MO can be quantified by the derivative of the MO energy with respect to nuclear coordinates will be developed. These results will then be validated against other classical approaches, previous studies and on the basis of experimental data for a panel of diatomic molecules. They will be extended to $\mathrm{HNC}, \mathrm{HCN}$ and $\mathrm{CH}_{3} \mathrm{CN}$ with a special attention to the hybrid "lone pairs". The bonding/antibonding character of the near-frontier molecular orbitals of well-known infrared spectroscopy probes such as $\mathrm{CO}$ and $\mathrm{CH}_{3} \mathrm{CN}$ has been indeed debated in the literature. ${ }^{[17]}$ Finally, a range of observable properties will be used to examine the variation of the MO characters of a ligand upon coordination to a charged metal centre; the corresponding perturbations will be mimicked either by a proton approach (a crude description of the ligand (Lewis base) - metal (Lewis acid) interaction), or by applying an electric field.

\section{Methods}

All calculations have been performed using the GAUSSIAN09 ${ }^{[18]}$ program, at the HF/6-311G** level unless otherwise specified. Derivatives of canonical MO energies $\varepsilon_{i}$ i have been computed numerically using finite difference of $+0.002 \AA$ of bond lengths with respect to the equilibrium value at the same calculation level, in order to satisfy Eq. 8. The restricted open HF (ROHF) method has been used for triplet species. For polyatomic molecules, the calculations were performed by variation of one bond length, dragging the separated ends with their original geometry in the equilibrium structure (constant interatomic distances and angles with respect to the head atom). This assumption differs from the one used by Averill and Painter for the definition of DOF. ${ }^{[15]}$

Unless otherwise indicated, the reported bond lengths $R_{\mathrm{e}}$ and their variations $\Delta R_{\mathrm{e}}$ by ionization or protonation (Tables 1, 2 and 6) are experimental values taken from the NIST data bank. When experimental data are not available, high level calculated values were reported from the literature or NIST.

\section{Results and discussion}

\section{Homonuclear diatomic molecules}

The derivatives of valence shell MO energies of a series of homonuclear diatomic molecules are reported in Table 1. These $\varepsilon^{\prime}$ i values are in accordance with the expected well-known MO nature, as follows. For instance, in the first period molecules, a large positive $\varepsilon^{\prime}{ }_{i}$ value $(0.164$ $\mathrm{au}$ ) is indeed calculated for the bonding $\sigma_{\mathrm{g}} \mathrm{MO}$ of $\mathrm{H}_{2}$ in agreement with the $\mathrm{H}-\mathrm{H}$ bond elongation 
from $0.741 \AA$ to $1.053 \AA$ upon removing an electron to give $\mathrm{H}_{2}{ }^{+}$. In contrast, a large negative value $(-0.275 \mathrm{au})$ is calculated for the antibonding $\sigma_{\mathrm{u}} \mathrm{MO}$ of $\mathrm{He}_{2}$. The latter is indeed a very weak Van der Waals complex with $R_{\mathrm{e}}=2.97 \AA$ and, after the loss of an electron from $\sigma_{\mathrm{u}}$, the molecular ion $\mathrm{He}_{2}{ }^{+}$with $R_{\mathrm{e}}=1.08 \AA$ is obtained.

Similarly, in molecules of periods 2 and 3, longer bonds result from removal of an electron from bonding MOs in $\mathrm{Li}_{2}\left(2 \sigma_{\mathrm{g}}\right), \mathrm{C}_{2}\left(1 \pi_{\mathrm{u}}\right)$ and $\mathrm{N}_{2}\left(3 \sigma_{\mathrm{g}}\right)$ which exhibit large positive $\varepsilon_{\mathrm{i}}^{\prime}$ values. The reverse holds for $\mathrm{F}_{2}, \mathrm{O}_{2}, \mathrm{~S}_{2}$ and $\mathrm{Cl}_{2}$ ( $\pi_{\mathrm{g}}$ antibonding in all cases). In the case of $\mathrm{P}_{2}$, the loss of an electron from the bonding HOMO $\pi_{\mathrm{u}}$ gives rise to the ${ }^{2} \Pi_{\mathrm{u}}$ ground state of $\mathrm{P}_{2}^{+}$exhibiting a longer bond than $\mathrm{P}_{2}$. The case of $\mathrm{Ne}_{2}$ is very similar to that of $\mathrm{He}_{2}$ : the neutral species is a weak Van der Waals complex with $R_{\mathrm{e}}=3.1 \AA$, that becomes a molecular ion $\mathrm{Ne}_{2}{ }^{+}$with $R_{\mathrm{e}}=1.75 \AA$ after losing an electron from the antibonding $3 \sigma_{\mathrm{u}} \mathrm{MO}$.

Table 1. Energy derivatives $\varepsilon_{\mathrm{i}}^{\prime}$ (au) of valence MOs of homonuclear diatomic molecules (HF/6$\left.311 \mathrm{G}^{* *}\right) ; R_{\mathrm{e}}(\AA)$ experimental equilibrium distance; $\Delta R_{\mathrm{e}}$ variation of the experimental equilibrium distance $(\AA)$ between neutral and cationic species in its ground state; in bold, $\varepsilon_{\text {i }}^{\prime}$ of the MO becoming singly occupied in the cation.

\begin{tabular}{llllllllll}
\hline $\mathbf{M O}$ & $\mathbf{H}_{2}$ & $\mathbf{H e}_{2}{ }^{\mathrm{a}}$ & $\mathbf{M O}$ & $\mathbf{L i}_{2}$ & $\mathbf{C}_{2}$ & $\mathbf{N}_{2}$ & $\mathbf{O}_{2}$ & $\mathbf{F}_{2}$ & $\mathbf{N e}_{2}{ }^{\mathbf{b}}$ \\
\hline $\mathbf{1} \sigma_{\mathrm{g}}$ & $\mathbf{0 . 1 6 4}$ & 0.305 & $\mathbf{2} \sigma_{\mathrm{g}}$ & 0.010 & 0.190 & 0.394 & 0.492 & 0.343 & 0.144 \\
$\mathbf{1} \sigma_{\mathrm{u}}$ & & $\mathbf{- 0 . 2 7 5}$ & $\mathbf{2} \sigma_{\mathrm{u}}$ & & -0.137 & -0.176 & -0.201 & -0.167 & -0.092 \\
& & & $\mathbf{3} \sigma_{\mathrm{g}}$ & & - & $\mathbf{0 . 0 4 7}$ & 0.111 & 0.215 & 0.131 \\
& & & $\mathbf{1} \pi_{\mathrm{u}}$ & & $\mathbf{0 . 1 2 2}$ & 0.238 & 0.209 & 0.136 & 0.063 \\
& & & $\mathbf{1} \pi_{\mathrm{g}}$ & & & & $\mathbf{- 0 . 1 9 9}$ & $\mathbf{- 0 . 1 2 5}$ & -0.066 \\
& & & $\mathbf{3} \sigma_{\mathrm{u}}$ & & & & & & $\mathbf{- 0 . 2 1 6}$ \\
$\boldsymbol{R}_{\mathrm{e}}$ & 0.741 & & & 2.672 & 1.245 & 1.098 & 1.208 & 1.412 & \\
$\Delta \boldsymbol{R}_{\mathrm{e}}$ & 0.312 & & & 0.37 & 0.056 & 0.018 & -0.091 & -0.090 & \\
\hline
\end{tabular}

Table 1 (continued)

\begin{tabular}{llll}
\hline $\mathbf{M O}$ & $\mathbf{P}_{2}$ & $\mathbf{S}_{2}$ & $\mathbf{C l}_{\mathbf{2}}$ \\
\hline $\mathbf{4} \sigma_{\mathrm{g}}$ & 0.115 & 0.077 & 0.156 \\
$\mathbf{4} \sigma_{\mathrm{u}}$ & -0.076 & -0.146 & -0.063 \\
$\mathbf{5} \sigma_{\mathrm{g}}$ & -0.008 & -0.019 & 0.096 \\
$\mathbf{2} \pi_{\mathrm{u}}$ & $\mathbf{0 . 0 7 2}$ & 0.042 & 0.068 \\
$\mathbf{2} \boldsymbol{\pi}_{\mathrm{g}}$ & & $\mathbf{- 0 . 0 6 6}$ & $\mathbf{- 0 . 0 5 6}$ \\
& & & \\
$\boldsymbol{R}_{\mathrm{e}}$ & 1.893 & 1.889 & 1.987 \\
$\Delta \boldsymbol{R}_{\mathrm{e}}$ & 0.092 & -0.064 & -0.096 \\
\hline${ }^{\mathrm{a}} R=1.0 \AA ;{ }^{\mathrm{b}} R=1.5 \AA ;$
\end{tabular}


Another interesting issue is the evolution of the $3 \sigma_{\mathrm{g}}$ and $5 \sigma_{\mathrm{g}}$ MOs of the series. The $3 \sigma_{\mathrm{g}}$ MOs have a maximum bonding character in $\mathrm{F}_{2}$ where the s-p hybridization is weaker, as a result of a large $2 \mathrm{~s}-2 \mathrm{p}$ gap in the $\mathrm{F}$ atom. This bonding character decreases in the following order $\mathrm{F}_{2}>\mathrm{O}_{2}>$ $\mathrm{Cl}_{2}>\mathrm{N}_{2}>\mathrm{P}_{2}>\mathrm{S}_{2}$ which follows the decrease of the s-p gap except for the latter two molecules. In the case of $\mathrm{P}_{2}$, the $5 \sigma_{\mathrm{g}} \mathrm{MO}$ can be considered as strictly non-bonding: $\varepsilon_{\mathrm{i}}{ }_{\mathrm{i}}$ is found slightly negative $(-0.008 \mathrm{au})$ with the $6-311 \mathrm{G}^{* *}$ basis set but slightly positive $(0.001 \mathrm{au})$ with the cc-pvtz Dunning's basis set. As a matter of fact, in a low lying excited state ${ }^{2} \Sigma_{\mathrm{g}}$ of $\mathrm{P}_{2}{ }^{+}$, resulting from the removal of a $5 \sigma_{\mathrm{g}}$ electron from the ground state of $\mathrm{P}_{2}$, the bond length is $1.893 \AA$, so unchanged with respect to $\mathrm{P}_{2}$.

\section{Heteronuclear diatomic molecules}

The energy derivatives of valence shell MOs of selected heteronuclear molecules possessing 10 and 12 electrons in their valence shell are listed in Table 2. In addition to their symmetry, the MOs are labelled as $n_{X}$ in relation to their main localization, in terms of "lone pairs". Chart 1 gathers the Lewis structures of the 10- and 12-valence electron species considered in the present study (Tables 1 and 2).

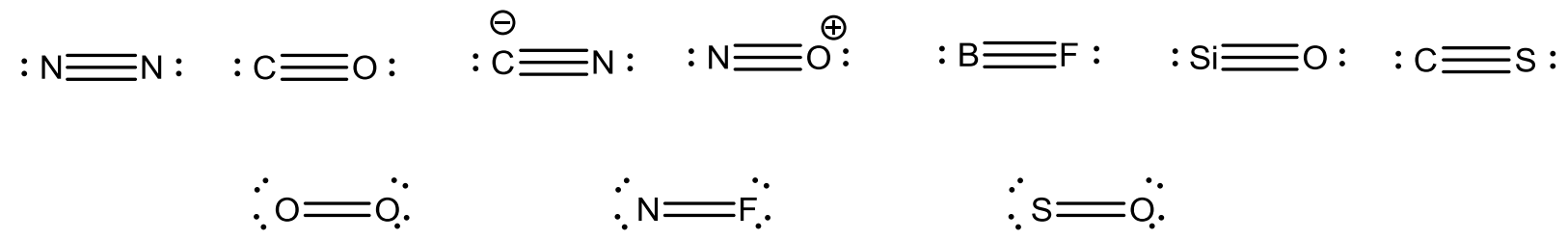

\section{Chart 1}

Table 2. Energy derivatives $\varepsilon_{\text {i }}(\mathrm{au})$ of valence MOs of selected heteronuclear diatomic species ((RO)HF/6-311G**) in their ground state; $R_{\mathrm{e}}(\AA)$ experimental equilibrium distance; $\Delta R_{\mathrm{e}}$ variation of the experimental equilibrium distance $(\AA)$ between neutral and cationic species in its ground state; in bold, $\varepsilon^{\prime}$ i of the MO becoming singly occupied in the cation.

\begin{tabular}{lllllllll}
\hline $\mathbf{M O}$ & $\mathbf{C O}$ & $\mathbf{C O}^{\mathbf{a}}$ & $\mathbf{M O}$ & $\mathbf{C N}^{-\mathbf{b}}$ & $\mathbf{M O}$ & $\mathbf{B F}$ & $\mathbf{M O}$ & $\mathbf{N O}^{+}$ \\
\hline $3 \sigma$ & 0.377 & 0.299 & $\mathbf{3 \sigma}$ & 0.232 & $\mathbf{3 \sigma}$ & 0.293 & $3 \sigma$ & 0.592 \\
$4 \sigma\left(\mathrm{n}_{\mathrm{O}}\right)$ & 0.052 & 0.008 & $\mathbf{4 \sigma}\left(\mathbf{n}_{\mathbf{N}}\right)$ & $\mathbf{- 0 . 1 1 4}$ & $\mathbf{4 \sigma}$ & 0.234 & $\mathbf{4 \sigma}$ & -0.053 \\
$\pi$ & 0.242 & 0.184 & $\pi$ & 0.136 & $\pi$ & 0.208 & $\pi$ & 0.317 \\
$5 \sigma\left(\mathrm{n}_{\mathrm{C}}\right)$ & $\mathbf{- 0 . 0 6 7}$ & $\mathbf{- 0 . 0 4 8}$ & $\mathbf{5 \sigma}\left(\mathbf{n}_{\mathbf{C}}\right)$ & $\mathbf{- 0 . 0 3 8}$ & $\mathbf{5 \sigma}\left(\mathbf{n}_{\mathbf{B}}\right)$ & $\mathbf{- 0 . 0 6 8}$ & $\mathbf{5 \sigma}\left(\mathbf{n}_{\mathbf{N}}\right)$ & $\mathbf{0 . 0 3 7}$ \\
& & & & & & & & \\
$\boldsymbol{R}_{\mathbf{e}}$ & 1.128 & & & 1.177 & & 1.267 & & 1.063 \\
$\boldsymbol{\Delta} \boldsymbol{R}_{\mathbf{e}}$ & -0.013 & & & -0.005 & -0.057 & & $0.034^{\mathrm{g}}$ \\
$\boldsymbol{\Delta} \boldsymbol{R}_{\mathbf{e}}$ & & & $-0.02^{\mathrm{c}}$ & & & \\
\hline
\end{tabular}


Table 2 (continued)

\begin{tabular}{|c|c|c|c|c|c|c|c|}
\hline MO & SiO & MO & CS & MO & $\mathbf{N F}^{f}$ & MO & SO $^{f}$ \\
\hline $5 \sigma$ & 0.176 & $5 \sigma$ & 0.186 & $3 \sigma$ & 0.373 & $5 \sigma$ & 0.296 \\
\hline $6 \sigma\left(n_{0}\right)$ & 0.024 & $6 \sigma\left(n_{S}\right)$ & -0.052 & $4 \sigma\left(n_{F}\right)$ & 0.042 & $6 \sigma\left(n_{0}\right)$ & -0.032 \\
\hline $3 \pi$ & 0.135 & $7 \sigma\left(\mathbf{n}_{C}\right)$ & -0.049 & $1 \pi$ & 0.217 & $7 \sigma\left(\mathbf{n}_{\mathrm{s}}\right)$ & 0.116 \\
\hline \multirow[t]{2}{*}{$7 \sigma\left(n_{S i}\right)$} & -0.016 & $3 \pi$ & 0.104 & $5 \sigma\left(\mathrm{n}_{\mathrm{N}}\right)$ & 0.021 & $3 \pi$ & 0.249 \\
\hline & & & & $2 \pi$ & -0.146 & $4 \pi$ & -0.101 \\
\hline$R_{\mathrm{e}}$ & 1.510 & & 1.534 & & 1.3170 & & 1.4811 \\
\hline$\Delta \boldsymbol{R}_{\mathrm{e}}$ & $0.006^{\mathrm{e}}$ & & -0.034 & & $-0.134^{d}$ & & -0.057 \\
\hline
\end{tabular}

${ }^{\mathrm{a}}$ B3LYP/6-311G** ${ }^{\mathrm{b}} 6-311+\mathrm{G}^{* *}{ }^{\mathrm{c}}$ loss of a $4 \sigma$ electron. ${ }^{\mathrm{d}}$ Calc. value taken from NIST databank ${ }^{\mathrm{e}}$ Taken from ref. 20. ${ }^{\mathrm{f}}$ Triplet ground state. ${ }^{\mathrm{g}}$ Taken frome ref 19.

The following observations emerge from the above calculations. In the series of 10 valence electrons species, we note that: (a) in $\mathrm{CO}$ and in $\mathrm{SiO}$, the $\mathrm{n}_{\mathrm{O}}$ is bonding while the HOMOs $\mathrm{n}_{\mathrm{C}}$ and $\mathrm{n}_{\mathrm{Si}}$ are antibonding; in contrast, both $\mathrm{n}_{\mathrm{C}}$ and $\mathrm{n}_{\mathrm{S}}$ are antibonding in the analogous molecule CS; (b) in $\mathrm{CN}^{-}$, both $\mathrm{n}_{\mathrm{C}}(\mathrm{HOMO})$ and $\mathrm{n}_{\mathrm{N}}$ are antibonding; (c) in $\mathrm{BF}$, the $\mathrm{n}_{\mathrm{B}}(\mathrm{HOMO})$ is antibonding; the $4 \sigma \mathrm{MO}$ is mainly located on fluorine, but cannot be viewed as a "lone pair" due to the strongly positive value of $\varepsilon^{\prime}$ i. (d) In contrast to the other molecules of the same period, the lone pair $\mathrm{n}_{\mathrm{N}} 5 \sigma$ of $\mathrm{NO}^{+}$is found bonding, which agree with the bond lengthening observed in the dication $\mathrm{NO}^{2+}{ }^{219]}$ These results qualitatively agree with previous calculations by Bickelhaupt et al. of $\mathrm{BP} 86 / \mathrm{TZP} \sigma \mathrm{MO}$ energy derivatives in the series $\mathrm{F}_{2}, \mathrm{~N}_{2}, \mathrm{CO}, \mathrm{BF}, \mathrm{NO}^{+}$and $\mathrm{CN}^{-}$, with absolute values of $\varepsilon^{\prime}{ }_{i}$ smaller by $10 \%$ to $40 \%$ than those reported here. ${ }^{[15]}$

The molecules NF and SO possess 12 electrons in their valence shell and have a triplet ground state, like $\mathrm{O}_{2}$. Due to electronegativity difference of fluorine and nitrogen, NF possesses two MOs with a marked $\sigma$ "lone pair" character $(4 \sigma$ and $5 \sigma)$, both slightly bonding. The $7 \sigma$ MO of $\mathrm{SO}$ is of $\mathrm{n}_{\mathrm{S}}$ type with a bonding character $\left(\varepsilon_{\mathrm{i}}^{\prime}=0.116 \mathrm{au}\right)$ close to that of the corresponding $3 \sigma_{\mathrm{g}}$ $\mathrm{MO}$ of $\mathrm{O}_{2}$, while the oxygen lone pair $(6 \sigma)$ is slightly antibonding.

In all but one of these cases, the sign of $\varepsilon^{\prime}$ i is in agreement with the bond length variation $\Delta R_{e}$ resulting from loss of the corresponding electron: whenever $\varepsilon^{\prime}{ }_{\mathrm{i}}$ is positive, $\Delta R_{e}$ is positive and vice versa. The only exception is $\mathrm{SiO}$, for which the ionization from the weakly antibonding $\mathrm{n}_{\mathrm{Si}}$ MO $\left(\varepsilon_{\mathrm{i}}=-0.016 \mathrm{au}\right)$ results in a slight lengthening (ca. $0.006 \AA$ according to experimental result) ${ }^{[20]}$ of the bond.

\section{Bonding or antibonding "lone pairs" of $\mathrm{CO}$ and $\mathrm{N}_{2}$.}

The comparison of the isoelectronic species $\mathrm{CO}$ and $\mathrm{N}_{2}$ is of special interest because $\mathrm{N}_{2}$ is also able to act as a ligand in a variety of metal complexes. ${ }^{[21]}$ Most textbooks ${ }^{[22]}$ consider the MO $3 \sigma_{\mathrm{g}}\left(\mathrm{n}_{\mathrm{N}}\right)$ of $\mathrm{N}_{2}$ as bonding and the HOMO $5 \sigma\left(\mathrm{n}_{\mathrm{C}}\right)$ of CO as antibonding, in agreement with the 
observed bond length variation upon ionization (Table 2). This result is further supported by the shortening of the $\mathrm{CO}$ bond upon protonation into $\mathrm{H}_{-} \mathrm{CO}^{+}$(see Table 6) ${ }^{[23]}$. Another experimental result in favour of the antibonding nature of the $\mathrm{n}_{\mathrm{C}} \mathrm{MO}$ is the observed $v(\mathrm{CO})$ stretching frequency in metal carbonyl complexes which is generally diminished by back donation from the metal into the $\pi^{*} \mathrm{MO}$ of $\mathrm{CO}^{[17 b]}$. In some electron-poor representatives, however, the $\sigma$ donation towards the metal $(\mathrm{M} \leftarrow \mathrm{CO})$ overcomes the back donation $(\mathrm{M} \rightrightarrows \mathrm{CO})$, leading to enhanced $v(\mathrm{CO})$ values. ${ }^{[24]}$

It should be emphasized that the (anti)bonding character of $\mathrm{n}_{\mathrm{C}}$ of $\mathrm{CO}$ has been the subject of debate in the literature. For instance, taking the overlap population as a criterion, Radius et al. ${ }^{[25]}$ attribute an antibonding character to $\mathrm{n}_{\mathrm{C}}$ of $\mathrm{CO}$; the same conclusion has been drawn for $\mathrm{n}_{\mathrm{N}}$ in $\mathrm{N}_{2}$. On the other hand, comparing the perturbations of $\mathrm{CO}$ when $\mathrm{H}^{+}$(or a positive point charge Q) approaches either the carbon or the oxygen atom, Frenking et al. ${ }^{[26,27]}$ take the opposite position with respect to the bonding character of $\mathrm{n}_{\mathrm{C}}$. These authors attribute the bond length variations of $\mathrm{CO}$ to perturbations of its $\pi$ MOs, becoming more or less bonding as it gets more or less symmetrical. We have attempted to probe this issue in the present study, as described below.

Let's first study the sensitivity of the $\varepsilon_{\text {i }}^{\text {i }}$ criterion to the basis set and to the calculation methods. To do this, we consider the $\varepsilon^{\prime}$ i values for several basis set HF calculations, EHMO and the semi empirical AM1 method in Table 3.

Table 3. Energy derivatives $\varepsilon$ ' (au) of MOs $\mathrm{n}_{\mathrm{C}}$ of $\mathrm{CO}$ and $\mathrm{n}_{\mathrm{N}}$ of $\mathrm{N}_{2}$ and bond length variation $\Delta R_{\mathrm{e}}$ at the same level of calculation (HF or DFT with the B3LYP functional)

\begin{tabular}{lcclccccc}
\hline & EHMO $^{\mathrm{a}}$ & STO-3G & AM1 & $\mathbf{3 - 2 1 G}^{*}$ & $\mathbf{6 - 3 1 1 G}$ & cc-pVTZ & cc-pVQZ & B3LYP \\
\hline $\mathbf{n}_{\mathbf{C}}(\mathbf{C O})$ & -0.079 & 0.042 & -0.051 & -0.057 & -0.067 & -0.066 & -0.067 & -0.048 \\
\hline $\boldsymbol{\Delta} \boldsymbol{R}_{\mathbf{e}}$ & - & 0.060 & -0.030 & -0.007 & -0.016 & -0.017 & -0.017 & -0.017 \\
& & & & & & & & \\
$\mathbf{n}_{\mathbf{N}}\left(\mathbf{N}_{\mathbf{2}}\right)$ & -0.095 & 0.135 & -0.069 & 0.067 & 0.047 & 0.050 & 0.046 & 0.025 \\
$\Delta \boldsymbol{R}_{\mathbf{e}}$ & - & 0.099 & -0.018 & 0.023 & 0.017 & 0.017 & 0.017 & 0.014 \\
\hline
\end{tabular}

Inspection of the results of Table 3 shows that $\varepsilon^{\prime}$ i values converge for triple zeta or higher basis set quality (maximum variations of 0.001 au for $\mathrm{n}_{\mathrm{C}}$ and 0.004 au for $\mathrm{n}_{\mathrm{N}}$ ). The HOMO of $\mathrm{N}_{2}$ is $1 \pi_{\mathrm{u}}$, but the $3 \sigma_{\mathrm{g}}\left(\mathrm{n}_{\mathrm{N}}\right)$ is quasi-degenerate, about 0.01 to 0.02 au lower in energy. The results from 6-311G**/B3LYP Kohn-Sham MOs are in qualitative agreement with HF ones, though weaker in absolute value.

In contrast, the $\varepsilon^{\prime}$ i values appear quite unreliable when computed with smaller basis sets or semi-empirical methods. For example, $\varepsilon_{\mathrm{i}}^{\prime}$ is positive for $\mathrm{n}_{\mathrm{C}}$ at the HF/STO-3G level while it is negative for $\mathrm{n}_{\mathrm{N}}$ at the EHMO and AM1 levels. Interestingly, these "anomalous" results are consistent with the bond length of the ions calculated at the same levels. Indeed, at the HF/STO$3 \mathrm{G}$ level the $\mathrm{CO}$ bond is longer by $0.06 \AA$ than in $\mathrm{CO}^{+}$than is $\mathrm{CO}$ whereas the $\mathrm{NN}$ bond length 
calculated at the AM1 level is shorter by $0.02 \AA$ in $\mathrm{N}_{2}{ }^{+}$than in $\mathrm{N}_{2}$. This comparison implies that when dealing with quasi non-bonding MOs, the bonding character may vary if calculated with a low quality method. It means that, if we refer to Figure 1, a small shift of the electron density from a bonding/antibonding area to another can be enough to change the sign of its force on nuclei.

Finally, based on $\varepsilon^{\prime}{ }_{i}$ values shown in Table 3, the $5 \sigma$ lone pair of $\mathrm{CO}$ is antibonding, whereas the $3 \sigma_{\mathrm{g}}$ one of $\mathrm{N}_{2}$ is bonding, also in agreement with the additive orbital force calculations of Bader et al. ${ }^{[28]}$ and results from Bickelhaupt. ${ }^{[15]}$

Figure 3 shows the continuous evolution of the characters of the valence shell MOs from CO to $\mathrm{N}_{2}$ by using fictitious molecules with variable nuclear charges. The charge of "oxygen" nucleus is replaced by $8-q$, down to $7(0<q<1)$ and the charge of "carbon" nucleus by $6+q$ up to 7. A basis set merging $\mathrm{C}$ and $\mathrm{O} 6-311 \mathrm{G}^{* *}$ atomic functions was used. The values of $\varepsilon^{\prime}{ }_{\mathrm{i}}$ are reported on Figure 3 as a function of $q$. We can see that the derivatives of the lower $3 \sigma / 2 \sigma_{\mathrm{g}} \mathrm{MO}$ and the $\pi$ MOs remain almost constant while the main evolution concerns the $4 \sigma / 2 \sigma_{\mathrm{u}}$ and $5 \sigma / 3 \sigma_{\mathrm{g}}$ MOs that exchange their bonding/antibonding characters. The bonding $3 \sigma_{\mathrm{g}} \mathrm{MO}$ of $\mathrm{N}_{2}$ becomes the $5 \sigma$ antibonding one of $\mathrm{CO}$ (though there is no phase inversion between $\mathrm{C}$ and $\mathrm{O}$ nuclei), by a shift of electron density towards the antibonding zone nearby carbon (see Figure 3 ).

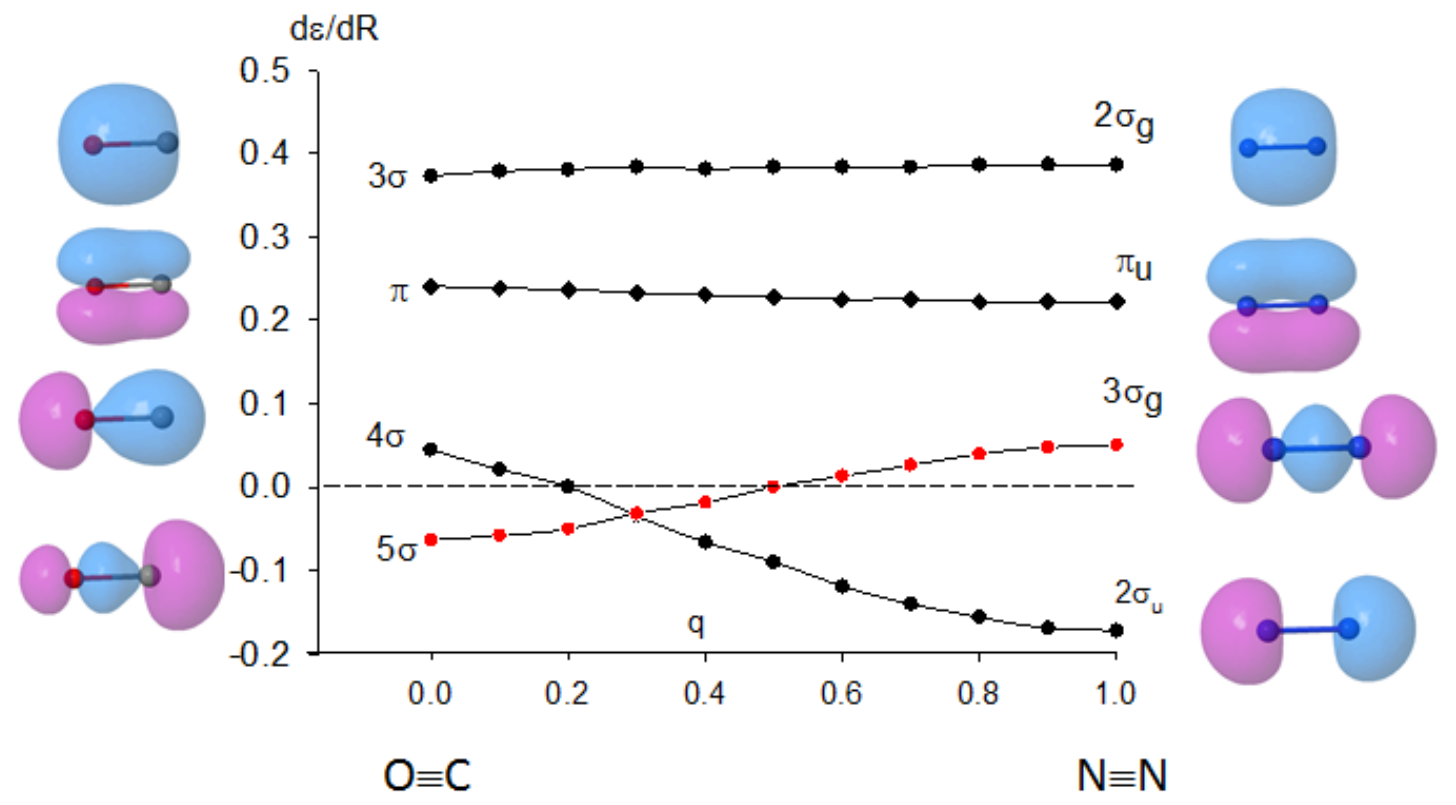

Figure 3. Evolution of $\mathrm{d} \varepsilon / \mathrm{d} R$ of valence MOs from $\mathrm{CO}$ to $\mathrm{N}_{2}$ by variation of the nuclear charges $8-q$ and $6+q$, as a function of $\mathrm{q}(0 \leq q \leq 1)$.

\section{Case of HCN and HNC}

Table 4 lists the calculated MO energy derivatives with respect to the $\mathrm{C}-\mathrm{H}$ and $\mathrm{C}-\mathrm{N}$ bond lengths of $\mathrm{HCN}$ and HNC. These calculations were performed by variation of one bond length, the other being kept constant. Examination of the values for $\mathrm{HCN}$ indicates that the $3 \sigma \mathrm{MO}$ is strongly 
bonding along $\mathrm{CN}$ and $4 \sigma$ is bonding along $\mathrm{CH}$ with a non-negligible antibonding character along $\mathrm{CN}$. The $5 \sigma \mathrm{MO}$, which is associated with the lone pair of nitrogen, is found to be slightly antibonding with respect to $\mathrm{CN}$ and only slightly bonding with respect to $\mathrm{CH}$. From its graphical representation (Figure 4), this MO could appear as essentially bonding on both $\mathrm{CN}$ and $\mathrm{CH}$ bonds. However, this counter intuitive result can be qualitatively understood as follows. Dealing with $\mathrm{CN}$, the two blue components of electron density are located in antibonding zones and overcome the bonding effect of the red one; dealing with $\mathrm{CH}$, the red component has an antibonding effect which almost compensates the blue bonding component on this bond.

Table 4. Energy derivatives $\mathrm{d} \varepsilon / \mathrm{d} R_{\mathrm{CN}}$ and $\mathrm{d} \varepsilon / \mathrm{d} R_{\mathrm{CH}}$ (au) of valence MOs of $\mathrm{HCN}$ and $\mathrm{HNC}$, with respect to $\mathrm{C} \equiv \mathrm{N}$ and $\mathrm{C}-\mathrm{H}$ bond lengths; $\mathrm{HF} / 6-311 \mathrm{G}^{* *}$ level of calculation.

\begin{tabular}{ccccll}
\hline \multicolumn{4}{c}{$\mathrm{H}-\mathrm{C} \equiv \mathbf{N}$} & \multicolumn{2}{c}{$\mathrm{C} \equiv \mathbf{N}-\mathbf{H}$} \\
\hline $\mathbf{M O}$ & $\mathbf{d} \boldsymbol{\varepsilon} / \mathbf{d} \boldsymbol{R}_{\mathrm{CN}}$ & $\mathbf{d} \boldsymbol{\varepsilon} / \mathbf{d} \mathbf{R}_{\mathrm{CH}}$ & $\mathbf{M O}$ & $\mathbf{d} \boldsymbol{\varepsilon} / \mathbf{d} \boldsymbol{R}_{\mathrm{CN}}$ & $\mathbf{d} \boldsymbol{\varepsilon} / \mathbf{d} \boldsymbol{R}_{\mathrm{NH}}$ \\
$3 \sigma$ & 0.255 & 0.003 & $3 \sigma$ & 0.255 & 0.057 \\
$4 \sigma$ & -0.077 & 0.209 & $4 \sigma$ & 0.068 & 0.232 \\
$\mathbf{5 \sigma}\left(\mathbf{n}_{\mathrm{N}}\right)$ & -0.030 & 0.017 & $\pi$ & 0.182 & 0.025 \\
$\pi$ & 0.170 & 0.008 & $\mathbf{5 \sigma}\left(\mathbf{n}_{\mathrm{C}}\right)$ & -0.111 & 0.021 \\
\hline
\end{tabular}

Moreover, at first glance, it may be also surprising that the $\pi$ MOs are found slightly bonding along $\mathrm{CH}\left(\mathrm{d} \varepsilon / \mathrm{d} R_{\mathrm{CH}}=0.008 \mathrm{au}\right)$, while their overlap is zero with the $1 \mathrm{~s} \mathrm{OA}$ of the $\mathrm{H}$ atom. It should be recalled, however, that i) the presence of $\mathrm{p}$ polarization basis functions on $\mathrm{H}$ allows a weak bonding interaction and ii) the $\pi$ density exerts a non-zero force on the $\mathrm{H}$ nucleus. The same phenomenon is observed in $\mathrm{HF}$ and $\mathrm{HCl}$, where the $\mathrm{p}$ lone pairs of $\mathrm{F}$ and $\mathrm{Cl}$ have a positive $\varepsilon_{\mathrm{i}}^{\prime}(0.055 \mathrm{au}$ and $0.013 \mathrm{au}$, respectively), in agreement with the observed lengthening of these bonds in the ${ }^{2} \Pi$ ground state of cations $\mathrm{HF}^{+}$and $\mathrm{HCl}^{+}(0.084 \AA$ and $0.04 \AA$ respectively). These results are also supported by orbital force calculations. ${ }^{[29,30]}$ From Figure 2 , it is clear that the $2 p$ density on the fluorine atom in HF is not equally spread in the bonding and antibonding regions. Indeed, it is difficult to predict whether this force is attractive or repulsive. 
$\mathrm{H}-\mathrm{C} \equiv \mathrm{N}$
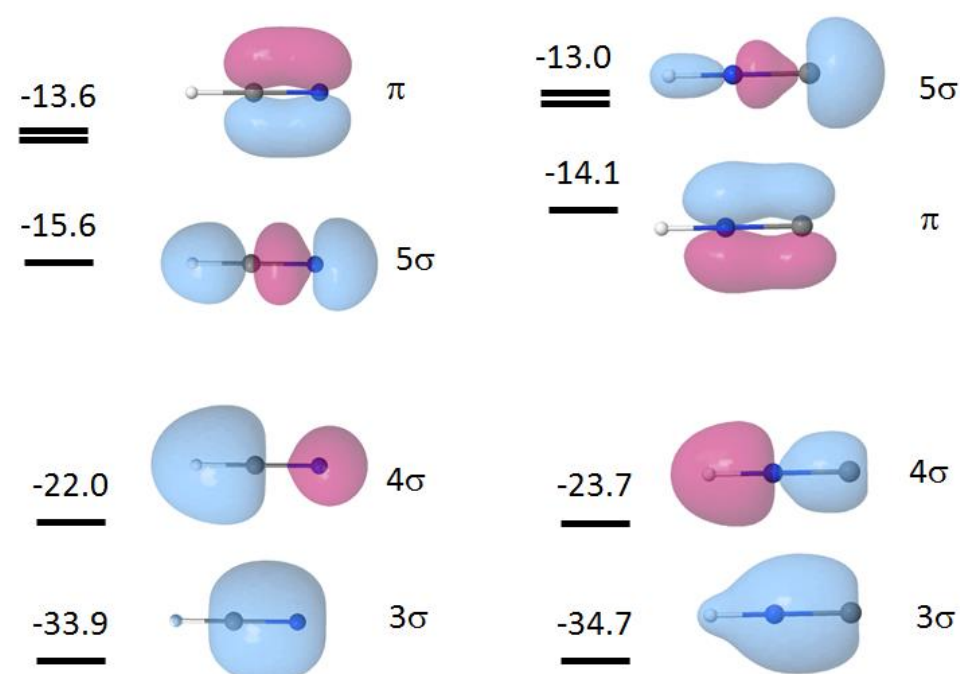

$\mathrm{H}-\mathrm{N} \equiv \mathrm{C}$

$-23.7$

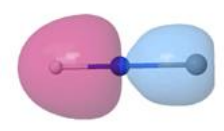

$4 \sigma$

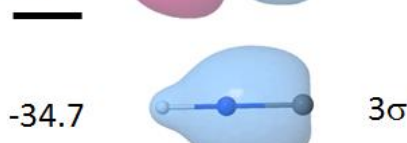

Figure 4. Valence shell MOs of $\mathrm{H}-\mathrm{CN}$ and $\mathrm{H}-\mathrm{NC}$ (only one of each $\pi$ degenerate set has been reported; energies in $\mathrm{eV} ; \mathrm{HF} / 6-311 \mathrm{G}^{* *}$ level of calculation).

The MO diagram of $\mathrm{HNC}$ exhibits some differences as compared to that of HCN. First, the $5 \sigma$, formally a carbon lone pair, is now the HOMO and becomes more antibonding on $\mathrm{CN}$, in contrast to what was observed in HCN. Second, the $4 \sigma$ becomes slightly bonding on CN. Again, the $\pi$ MOs are found to have a bonding character along $\mathrm{NH}\left(\mathrm{d} \varepsilon / R_{\mathrm{NH}}=0.025 \mathrm{au}\right)$ though their overlap with the valence $1 \mathrm{~s}$ MO of hydrogen is zero.

\section{Acetonitrile $\mathrm{CH}_{3} \mathrm{CN}$}

The bonding character of the nitrogen lone pair of nitriles is of interest in order to study their coordination chemistry. In Table 5, we report $\mathrm{MO}$ energy derivatives of $\mathrm{CH}_{3} \mathrm{CN}$ with respect to each bond length, all other internal coordinates being kept constant, with $6-311 \mathrm{G}^{* *}$ and ccpVQZ Dunning's basis sets.

These data allow us to attribute the character(s) of each MO with respect to each bond, and do so more readily and confidently than by simple visual examination (cf. Figure 5). The $7 \mathrm{a}_{1} \mathrm{MO}$ (HOMO - 2) essentially describes the lone pair of nitrogen; it is antibonding along $\mathrm{CN}(-0.010$ au and $-0.015 \mathrm{au}$ according to the basis set). This antibonding character is weak as compared to that of the HOMO of CO (-0.07 au) and also weaker than that of the corresponding MO of HCN ($0.03 \mathrm{au}$ ). The $6 \mathrm{a}_{1} \mathrm{MO}$, which is more strongly antibonding along $\mathrm{CN}$ and bonding along $\mathrm{CC}$ and $\mathrm{CH}$, possesses also a small lobe pointing from nitrogen. 
Table 5. Energy derivatives $\mathrm{d} \varepsilon / \mathrm{d} R_{\mathrm{XY}}(\mathrm{au})$ of valence $\mathrm{MOs}$ of $\mathrm{CH}_{3} \mathrm{CN}$ with respect to their bond lengths (a) HF/6-311G** (b) HF/cc-pVQZ.

\begin{tabular}{|c|c|c|c|c|c|c|}
\hline \multirow[t]{2}{*}{ MO } & \multicolumn{2}{|c|}{$\mathrm{d} \varepsilon / \mathrm{d} R_{\mathrm{CN}}$} & \multicolumn{2}{|c|}{$\mathrm{d} \varepsilon / \mathrm{d} R_{\mathrm{Cc}}$} & \multicolumn{2}{|c|}{$\mathrm{d} \varepsilon / \mathrm{d} R_{\mathrm{CH}}$} \\
\hline & (a) & (b) & (a) & (b) & (a) & (b) \\
\hline $4 \mathbf{a}_{1}\left(\sigma_{\mathrm{CN}}\right)$ & 0.255 & 0.249 & 0.010 & 0.010 & -0.004 & -0.002 \\
\hline $5 \mathbf{a}_{1}\left(\sigma_{\mathrm{CH}}\right)$ & -0.023 & -0.025 & 0.111 & 0.111 & 0.146 & 0.147 \\
\hline $6 \mathbf{a}_{1}\left(\sigma_{C C}\right)$ & -0.069 & -0.071 & 0.081 & 0.081 & 0.068 & 0.069 \\
\hline 1e $\left(\pi_{\mathrm{CH}}\right)$ & -0.004 & -0.006 & 0.041 & 0.042 & 0.147 & 0.148 \\
\hline $7 \mathbf{a}_{1}\left(\mathbf{n}_{N}\right)$ & -0.010 & -0.015 & 0.008 & 0.007 & -0.004 & -0.003 \\
\hline $2 \mathrm{e}\left(\pi_{\mathrm{CN}}\right)$ & 0.157 & 0.156 & -0.029 & -0.029 & 0.014 & 0.015 \\
\hline
\end{tabular}

It is worth noting that the $1 \mathrm{e}$ MOs associated with $\mathrm{CH}_{3}$ bonds $\left(\mathrm{d} \varepsilon / \mathrm{d} R_{\mathrm{CH}} \approx 0.15 \mathrm{au}\right)$ are also bonding along $\mathrm{CC}\left(\mathrm{d} \varepsilon / \mathrm{d} R_{\mathrm{CC}} \approx 0.04 \mathrm{au}\right)$ and slightly antibonding along $\mathrm{CN}\left(\mathrm{d} \varepsilon / \mathrm{d} R_{\mathrm{CN}}=-0.004-\right.$ $-0.006 \mathrm{au})$ in agreement with the classical scheme of hyperconjugation:
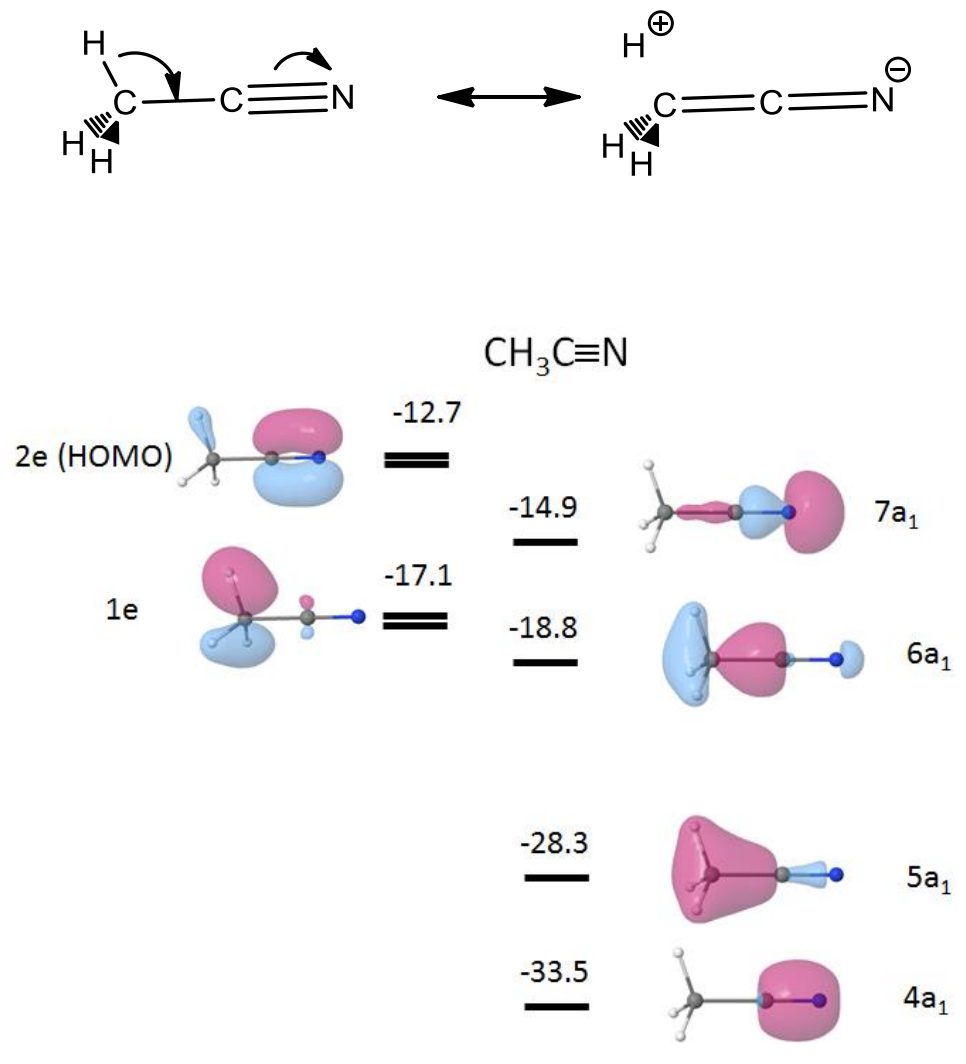

Figure 5. Valence shell occupied $\mathrm{MOs}$ of $\mathrm{CH}_{3} \mathrm{CN}$ (energy in $\mathrm{eV}$; only one of each degenerate set has been reported; $\mathrm{HF} / 6-311 \mathrm{G}^{* *}$ level of calculation). 


\section{Canonical MO energy derivative: a reliable criterion of bonding character}

From the results of Tables 3 and 5 obtained with various basis sets, it is reasonable to conclude that $\varepsilon^{\prime}$, calculated with a triple zeta quality basis set, is a reliable parameter associated with each MO. Note that the differences in $\varepsilon^{\prime}$ i values calculated with various TZ and QZ basis sets are no more than $0.002 \mathrm{au}$ in most cases, with a maximum of $0.006 \mathrm{au}$. In other words, the uncertainty on these results is about 0.005 au in absolute value.

From Tables 1 and 2, it has been shown that the sign of $\varepsilon^{\prime}{ }_{i}$ allows the prediction of the effect of ionization from the $i^{\text {th }}$ spin orbital on the bond length: when $\varepsilon_{\mathrm{i}}>0$, the bond length increases, which is consistent with a bonding MO in the sense of Mulliken. Moreover, a correlation is found between $\varepsilon_{\mathrm{i}}^{\prime}$ and the experimental relative bond length variation, as long as this variation is small $(<10 \%)$. This correlation, shown in Figure 6 , includes the results of Tables 1 and 2 (except $\mathrm{H}_{2}$ and $\mathrm{Li}_{2}$ ), $\mathrm{HF}$ and $\mathrm{HCl}$.

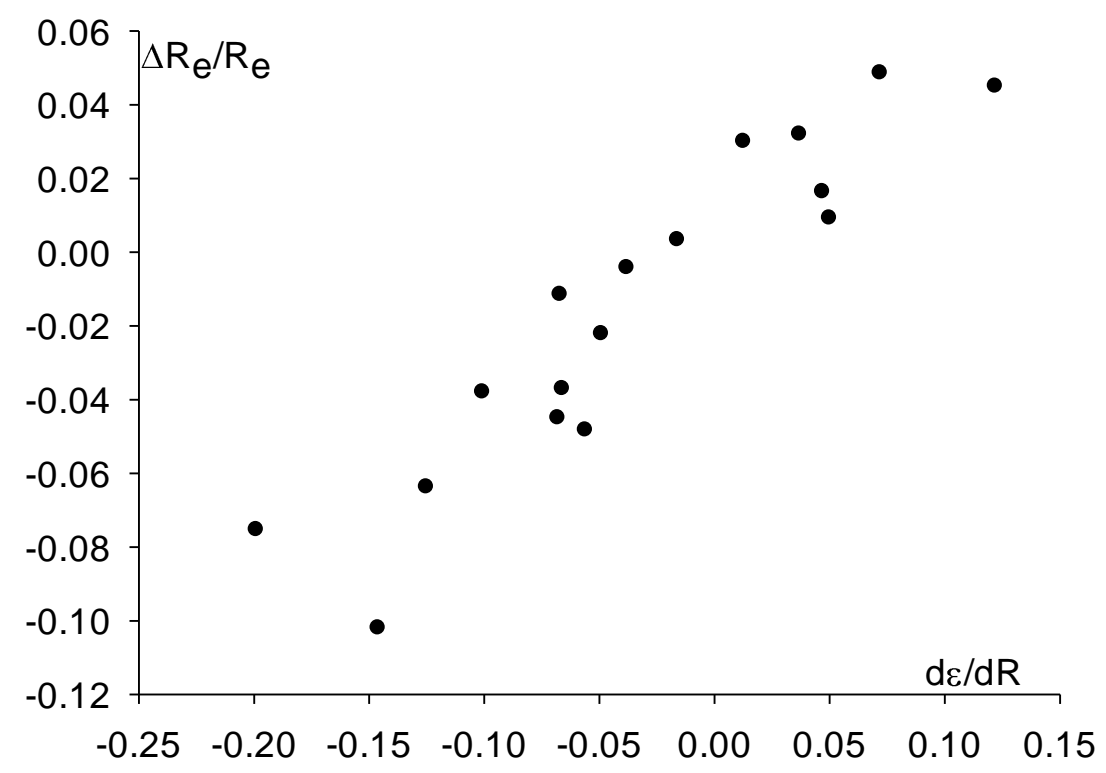

Figure 6. Experimental relative variation $\Delta R_{\mathrm{e}} / R_{\mathrm{e}}$ of the bond length by ionization, as a function of the $\mathrm{MO}$ energy derivative $\mathrm{d} \varepsilon / \mathrm{d} R(\mathrm{au})$ of the removed electron, in a series of diatomic molecules $\left(\mathrm{HF} / 6-311 \mathrm{G}^{* *}\right)$.

There is indeed a continuum from strongly bonding to strongly antibonding MOs (strictly nonbonding MOs, with $\mathrm{d} \varepsilon / \mathrm{d} R=0.0000 \ldots$, are theoretical situations of negligible occurrence in the molecular realm). Nevertheless, we can propose rough landmarks for the bonding characteristics of MOs of diatomic molecules. In second period diatomic molecules, a mean $\varepsilon$ ' value of ca. 0.30 au is found for $\sigma$ bonding MOs and 0.20 for $\pi$ bonding MOs; absolute values of $\varepsilon$ ' less than 0.1 au refer to essentially "non-bonding" MOs. These values are divided by about 3 when dealing with third period diatomic molecules whose bonds are significantly weaker, and by about 1.5 for 
molecules mixing these both elements. In polyatomic molecules, such a classification becomes difficult because several MOs may contribute almost equally to the same bond (see Table 5).

\section{Perturbation by electron acceptors: protonation, proton interaction and effect of an electric} field

\section{Protonation.}

In addition to the complete removal of an electron, the experimental consequences of a partial electron transfer from a $\mathrm{MO}$ to an electrophile are possibly rationalized from the bonding/antibonding nature of this MO. The simplest electrophile is $\mathrm{H}^{+}$, which can be viewed as the simplest model of a metal centre, and one could assume that the main effects of protonation can be predicted according to the character of the lone pair to be protonated. For a bonding lone pair, electron density is partly removed: a lengthening of the bond and other effects qualitatively similar to ionization are generally expected. It is clearly visible for seven of the eight entries of Table 6.

Table 6. Values of $\varepsilon^{\prime}{ }_{\mathrm{i}}=\mathrm{d} \varepsilon_{\mathrm{i}} / \mathrm{d} R_{\mathrm{XY}}$ (au) of the lone pair in the free molecule $\mathrm{X} \equiv \mathrm{Y}$ and experimental variation $\Delta R_{\mathrm{XY}}(\AA)$ of $\mathrm{XY}$ bond length by protonation; $\left((\mathrm{HCNH})^{+}\right.$can be considered either as protonated $\mathrm{HCN}$ or as protonated $\mathrm{HNC})$.

\begin{tabular}{lllllllll}
\hline $\mathbf{R}-\mathbf{H}^{+}$ & ${ }^{+} \mathbf{H}-\mathbf{C} \equiv \mathbf{O}$ & $\mathbf{C} \equiv \mathbf{O}-\mathbf{H}^{+}$ & $\mathbf{N} \equiv \mathbf{N}-\mathbf{H}^{+}$ & $\mathbf{H}-\mathbf{C} \equiv \mathbf{N}$ & $\mathbf{C} \equiv \mathbf{N}-\mathbf{H}$ & $\mathbf{H C} \equiv \mathbf{N}-\mathbf{H}^{+}$ & ${ }^{+} \mathbf{H}-\mathbf{C} \equiv \mathbf{N H}$ & $\mathbf{C H}_{3} \mathbf{C} \equiv \mathbf{N}-\mathbf{H}^{+}$ \\
\hline $\boldsymbol{\varepsilon}_{\mathbf{i}}$ & -0.067 & 0.052 & 0.047 & -0.114 & -0.038 & -0.030 & -0.111 & -0.010 \\
$\Delta \boldsymbol{R}_{\mathbf{X Y}}$ & $-0.023^{\mathrm{a}}$ & $0.029^{\mathrm{a}}$ & $-0.005^{\mathrm{b}}$ & -0.021 & -0.004 & $-0.070^{\mathrm{c}}$ & $-0.035^{\mathrm{c}}$ & $-0.011^{\mathrm{d}}$ \\
\hline
\end{tabular}

${ }^{\mathrm{a}}$ From ref. $23 ;{ }^{\mathrm{b}}$ From ref $32 ;{ }^{\mathrm{c}}$ From ref. $31 ;{ }^{\mathrm{d}}$ Calculated value (B3LYP/6-311G**)

As anticipated, the protonations on each side of $\mathrm{CO}$ have opposite effects on the $\mathrm{C}$-O bond length, ${ }^{[23]}$ in agreement with the opposite characters of the corresponding lone pairs. In contrast, both protonations of $\mathrm{CN}^{-}$shortens the $\mathrm{CN}$ bond ${ }^{[31]}$, in agreement with the antibonding character of both $\mathrm{C}$ and $\mathrm{N}$ lone pairs. For $\mathrm{N}_{2}$, we observe that the protonation slightly shortens the $\mathrm{NN}$ bond ${ }^{[32]}$, in contrast to the ionization. This can be understood by considering that, due to the symmetry of $\mathrm{N}_{2}$, the protonation withdraws electrons as well from the bonding $3 \sigma_{\mathrm{g}}$ as from the antibonding $2 \sigma_{\mathrm{u}}$ (see Fig. 3).

\section{Proton approach and electric field.}

Goldman and Krogh-Jesperson have argued that the increase of the force constant of $\mathrm{CO}$ in cationic complexes can be essentially described by an electrostatic effect (exerted by a point charge), and not by $\sigma$-donation from an antibonding MO. ${ }^{[33]}$ In fact, from a force point of view, these phenomena result in pulling electron density from the ligand towards the cation, and could appear as closely related. Nevertheless, we will examine below the impact on $\mathrm{CO}$ and $\mathrm{CH}_{3} \mathrm{CN}$ of an approaching proton and of embedding these molecules into an electric field (which can be 
actually considered homogeneous if exerted by a sufficiently remote and high point charge on the bond axis).

In Figure 7, we report the $\mathrm{MO}$ energy derivatives of $\mathrm{CO}$ when a proton is approached to carbon or oxygen atom. In both cases, the derivatives of the energies of $3 \sigma\left(\sigma_{\mathrm{CO}}\right)$ and $\pi$ MOs increase slightly. In contrast, the MOs $4 \sigma$ and $5 \sigma$ associated with the $C$ and $O$ lone pairs are strongly perturbed. When $\mathrm{H}^{+}$approaches the carbon atom, $\mathrm{n}_{\mathrm{C}}$ becomes less antibonding and finally slightly bonding, whereas $\mathrm{n}_{\mathrm{O}}$ becomes less bonding an finally antibonding. When $\mathrm{H}^{+}$approaches the oxygen atom, these trends are qualitatively strictly inverted.

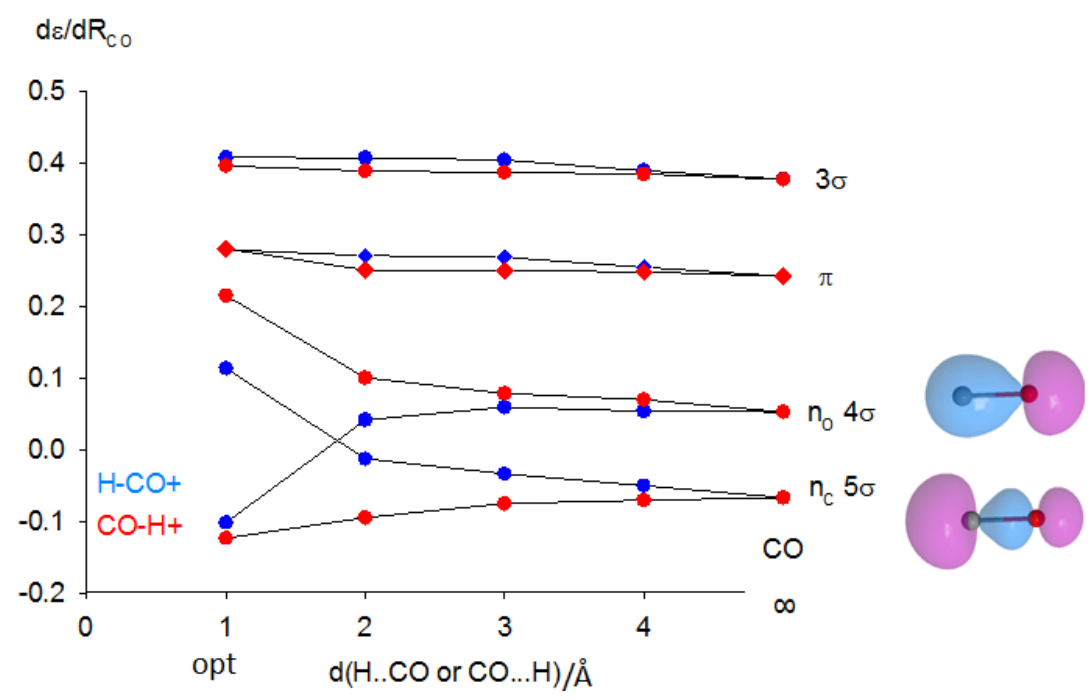

Figure 7. $\mathrm{MO}$ energy derivative $\mathrm{d} \varepsilon / \mathrm{d} R_{\mathrm{CO}}(\mathrm{au})$ for $\mathrm{H}^{+} \ldots \mathrm{CO}$ (blue) and $\mathrm{CO} \ldots \mathrm{H}^{+}$(red) at various $\mathrm{H} \ldots \mathrm{C}$ (resp. O...H) $d$ distances $(\AA)$ and optimized (opt) geometry.

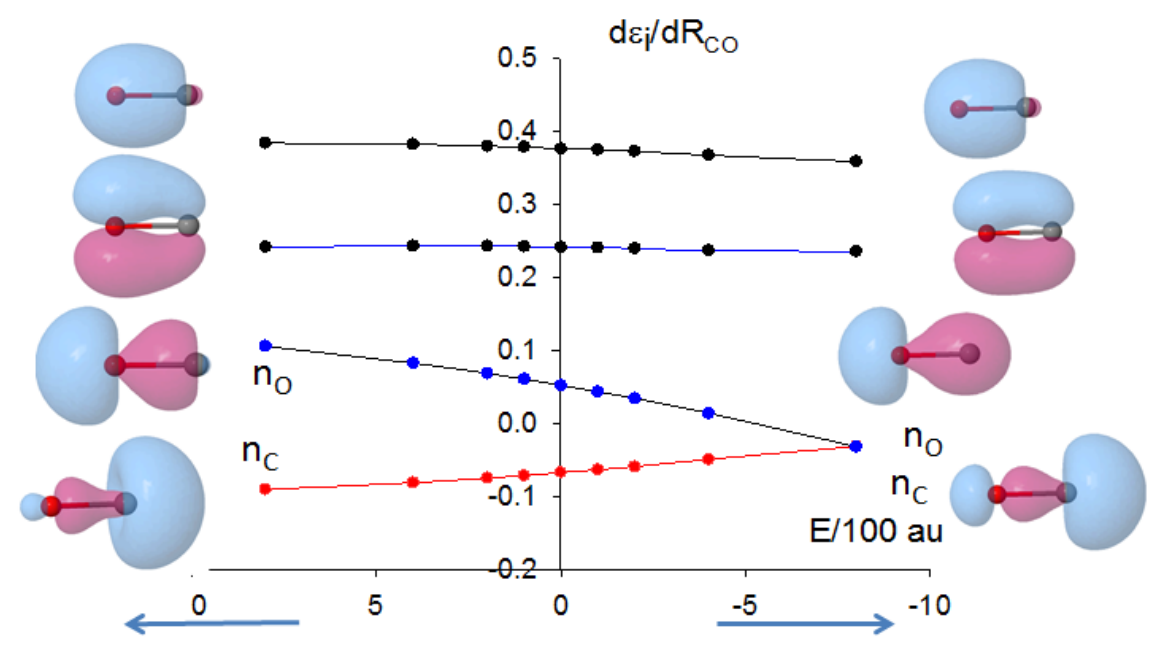

Figure 8. Effect of an electric field $E$ on $\mathrm{MO}$ energy derivatives $\mathrm{d} \varepsilon / \mathrm{d} R_{\mathrm{CO}}$ (au) of $\mathrm{CO}$. The arrows indicate the direction of electron shift. 
The effect of an electric field appears to be quite similar to proton approach (Figure 8). Thus in the left segment on the Figure 8 (positive field) the electrons are shifted from oxygen to carbon, which corresponds to red points in Figure $7\left(\mathrm{CO} \ldots \mathrm{H}^{+}\right)$. We observe that the $\varepsilon^{\prime}$ of $\pi$ MOs undergo relatively small variations even though they are significantly distorted. We observe also a divergent variation of $\varepsilon^{\prime}$ for $\mathrm{n}_{\mathrm{C}}$ and $\mathrm{n}_{\mathrm{O}}$.

The right segment of Figure 8 (negative field) corresponds to electron shift from carbon to oxygen (cf. blue points $\mathrm{H}^{+} \ldots \mathrm{CO}$ approach in Figure 7). It results in a convergent variation of $\varepsilon^{\prime}$ of $\mathrm{n}_{\mathrm{C}}$ and $\mathrm{n}_{\mathrm{O}}$. To these monotonous variations corresponds a monotonous variation of the calculated CO vibration frequency and bond length (see Figure 9 and 10) which follow the energy derivative of the HOMO $n_{C}$, despite the decreasing bonding character of $n_{O}$. The variation of $v_{\mathrm{CO}}$ suggests that a maximum of frequency should be reached for a field value of ca. $0.1 \mathrm{au}$, in agreement with previous reports. ${ }^{[34]}$

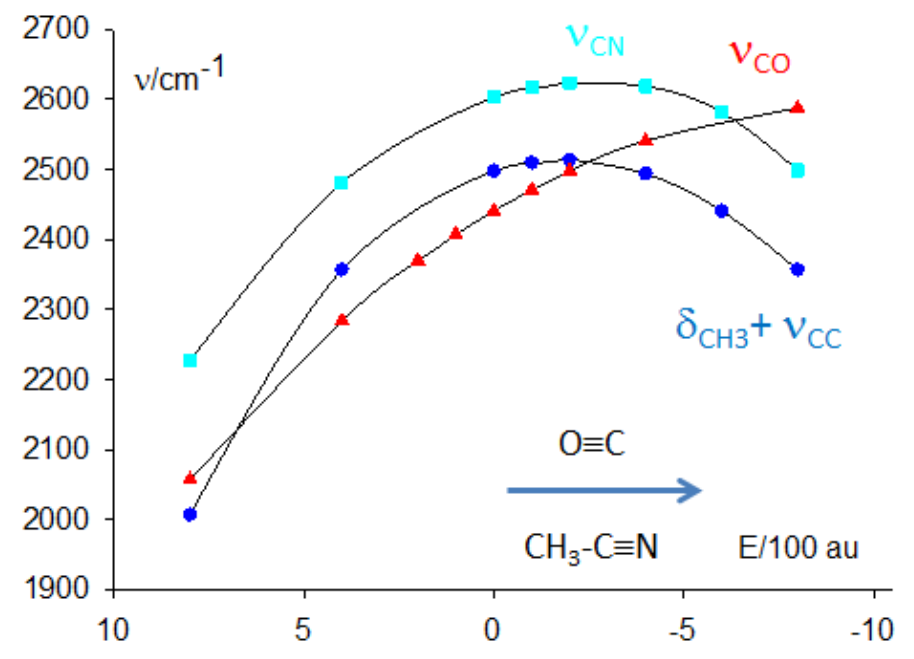

Figure 9. Calculated vibration $\left(\mathrm{HF} / 6-311 \mathrm{G}^{*}\right)$ frequencies of $\mathrm{CO}$ and $\mathrm{CH}_{3} \mathrm{CN}$ as a function of electric field $E$ oriented along molecular axis; the arrow indicates the direction of electron shift for $E<0$. 


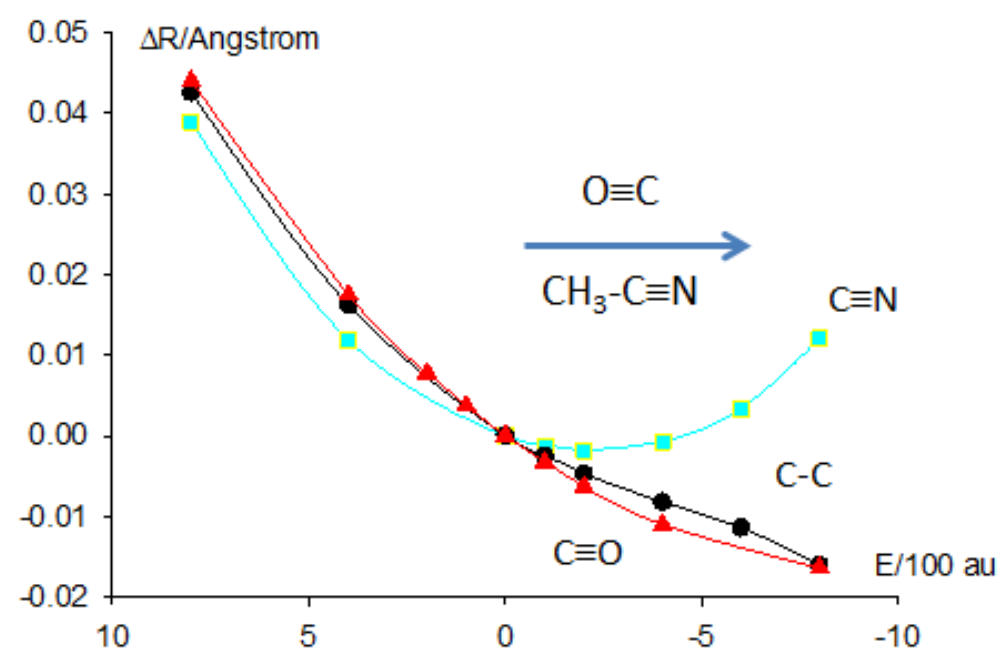

Figure 10. Variation of bond lengths $\Delta R(\AA)$ in $\mathrm{CO}$ and $\mathrm{CH}_{3} \mathrm{CN}$ as a function of electric field $E$ oriented along the molecular axis; the arrow indicates the direction of electron shift for $E<0$.

The situation is quite different when we consider $\mathrm{CH}_{3} \mathrm{CN}$, as displayed in Figure 11. When a proton approaches the nitrogen atom, the bonding character along $\mathrm{CN}$ of most of the MOs is noticeably perturbed, especially $4 \mathrm{a}_{1}\left(\sigma_{\mathrm{CN}}\right)$ and both e $(\pi)$ MOs. Also, the variation of $\mathrm{d} \varepsilon / \mathrm{d} R_{\mathrm{CN}}$ of $7 \mathrm{a}_{1}$ (nitrogen lone pair) $5 \mathrm{a}_{1}$ and $6 \mathrm{a}_{1}$ is no longer monotonous.

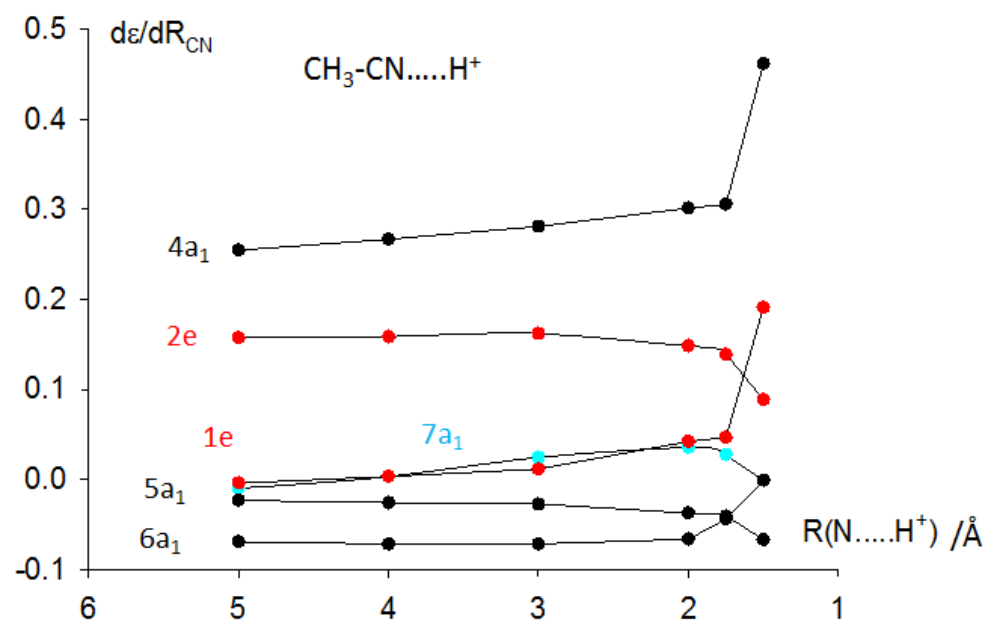

Figure 11. $\mathrm{MO}$ energy derivative $\mathrm{d} \varepsilon / \mathrm{d} R_{\mathrm{CN}}$ (au) for $\mathrm{CH}_{3} \mathrm{CN} \ldots \mathrm{H}^{+}$at various $\mathrm{N} \ldots \mathrm{H}^{+}$distances $(\AA)$.

The effect of an electric field (Figure 12) gives a deeper insight on these phenomena especially in the region of negative field (electron shift from $\mathrm{C}$ to $\mathrm{N}$ ); a crossing occurs between the two sets of $\pi$ MOs which exchange their bonding characters on $\mathrm{CH}_{3}$ and $\mathrm{CN}$. These dramatic changes arise from the high polarizability of the $\pi$ hyperconjugated system, as compared with $\mathrm{CO}$ (the 
dipole moment is increased by 7.5 $\mathrm{D}$ for $\mathrm{CH}_{3} \mathrm{CN}$ and $2.8 \mathrm{D}$ for $\mathrm{CO}$ by a field of $0.08 \mathrm{au}$ ). As with the proton approach, the energy derivative of the $7 \mathrm{a}_{1}$ lone pair reaches a maximum bonding for a field value of ca. -0.04 au.

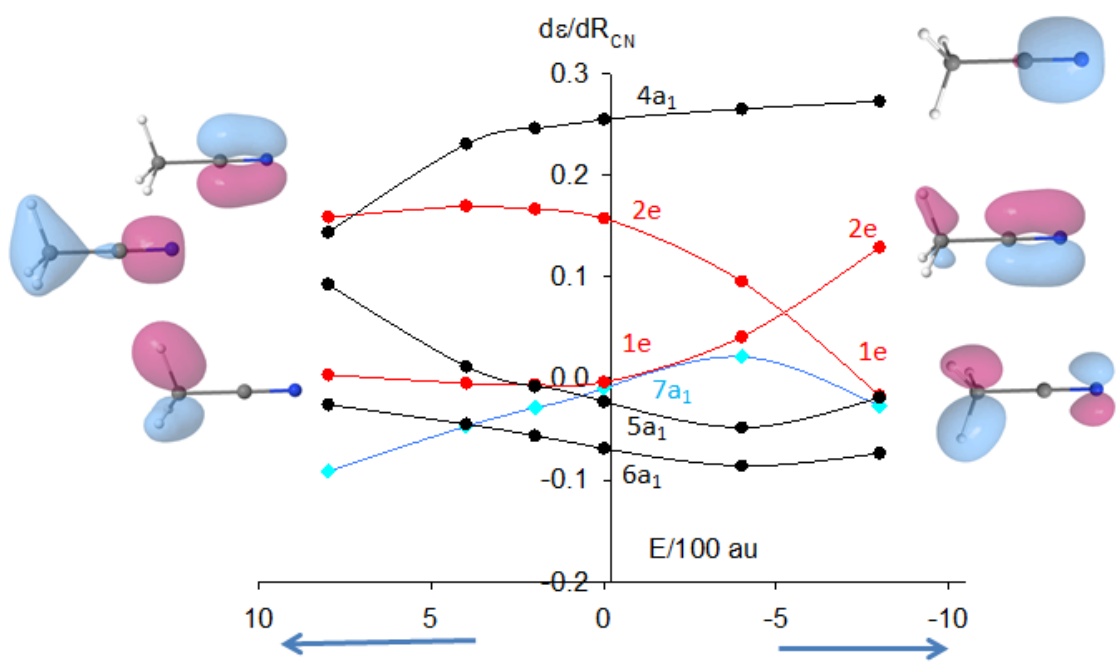

Figure 12. Effect of an electric field $E$ on $\mathrm{MO}$ energy derivatives $\mathrm{d} \varepsilon / \mathrm{d} R_{\mathrm{CN}}(\mathrm{au})$ in $\mathrm{CH}_{3} \mathrm{CN}$. The arrows indicate the direction of electron shift.

Figure 9 shows the variation of calculated vibrational frequencies of $\mathrm{CH}_{3} \mathrm{CN}$ as a function of the electric field E. The $\mathrm{CN}$ frequency does not vary monotonously in the electric field range considered and a maximum positive shift is observed at ca. $20 \mathrm{~cm}^{-1}$ for a field of ca. -0.025 au with respect to free acetonitrile at zero field. The same order of magnitude of these values (20-30 $\mathrm{cm}^{-1}$ ) is observed experimentally ${ }^{[35,36]}$, though in some cases much higher values have been measured ${ }^{[17 \mathrm{c}, \mathrm{d}]}$. The equilibrium bond length of $\mathrm{CN}$ is minimal at about the same value of the electric field (Figure 10). It is remarkable that these extrema also occur at about the same field value as the maximum of $\varepsilon^{\prime}$ of the lone pair $7 \mathrm{a}_{1}$. Nevertheless, this result must be considered with caution, because other MOs undergo strong variations in their bonding character and in opposite directions. Furthermore, the frequencies of free $\mathrm{CH}_{3} \mathrm{CN}$ at 2252 and $2293 \mathrm{~cm}^{-1}$ are attributed to a Fermi resonance between the fundamental $v_{\mathrm{CN}}$ and the combination $\left(v_{\mathrm{CC}}+\delta_{\mathrm{CH} 3}\right)$. These fundamental vibrations themselves involve the participation, in their normal coordinate, of other vibrators which are also strongly perturbed by an electric field as it can be seen in Figure 9. Yet, Table 5 suggests that the $7 \mathrm{a}_{1} \mathrm{MO}$, as well as $6 \mathrm{a}_{1}$, antibonding along $\mathrm{CN}$, should have also a noticeable bonding character along $\mathrm{CC}$. Indeed, the $\mathrm{CC}$ bond is found shorter in the presence of proton or electric field and decreases monotonously with the electric field (Figure 10).

\section{Conclusion}

Our results have shown that, on the basis of the Koopmans theorem, the derivative $\varepsilon^{\prime}{ }_{i}$ of the energy of a canonical MO $\phi_{\mathrm{i}}$ with respect to the distance $R$ between two nuclei A and $\mathrm{B}$ can be 
considered as a good index of the bonding/antibonding character of this MO along $\mathrm{A}-\mathrm{B}$. Thus, the sign of $\varepsilon^{\prime}$ allows the prediction of the sign of variation of the bond length A-B of diatomic molecules by ionisation, which is itself a criterion of the bonding character. The same conclusion generally holds for the effect of protonation on the bond length. These derivatives can be easily computed and their results can be extended to any geometrical deformation of a polyatomic molecule. On this basis, the HOMOs $3 \sigma_{\mathrm{g}}$ of $\mathrm{N}_{2}$ and $5 \sigma$ of $\mathrm{NO}^{+}$are found to be bonding, whereas the HOMO $5 \sigma$ of $\mathrm{CO}$ is found to be antibonding. The lone pairs of BF, CS, $\mathrm{CN}^{-}, \mathrm{HCN}, \mathrm{HNC}$ and $\mathrm{CH}_{3} \mathrm{CN}$ are also more or less antibonding. In polyatomic molecules, where MOs are generally delocalized on several centres, the derivatives $\varepsilon^{\prime}{ }_{i}$ with respect to each bond length indicate the relative bonding (or antibonding) contribution of the $\phi_{\mathrm{i}} \mathrm{MO}$ to this bond.

We have modelled the coordination to a cationic metal centre either by proton interaction or by embedding the ligand into an electric field. The results presented here support the current idea that qualitative predictions of bond length and vibration frequency variations of ligands can be done by considering the bonding/antibonding character of MOs mainly interacting with the metal, provided the ligand is a diatomic molecule such as $\mathrm{CO}$. In other cases, like $\mathrm{CH}_{3} \mathrm{CN}$, several MOs are perturbed upon complexation, resulting in balanced effects on bond strengths and on the corresponding vibrators much or less coupled in the normal coordinates.

Moreover, canonical MOs are defined within HF approximation and their explanatory power is thus a priori restricted to phenomena correctly depicted, at least qualitatively, at this level of calculation.

We believe that these results open broad perspectives for experimentalists interrogating the nature of the bonding between acceptor and donor partners, especially in the field of coordination chemistry, where the nature of M-L bond is of particular significance. ${ }^{[37]}$ It would be of primary interest to examine how the bonding/antibonding character of MOs of a given ligand is affected upon coordination to a 'real' metal centre, and the possible back-donation of the metal towards the ligand may interfere.

KEYWORDS: Molecular orbitals, bonding criterion, donor-acceptor interaction, diatomic molecules, acetonitrile.

\section{References and Notes}

[1] IUPAC. Compendium of Chemical Terminology, 2nd ed. (the "Gold Book"). Compiled by A. D. McNaught and A. Wilkinson. Blackwell Scientific Publications, Oxford (1997). XML online corrected version: http://goldbook.iupac.org (2006-) created by M. Nic, J. Jirat, B. Kosata; updates compiled by A. Jenkins. ISBN 0-9678550-9-8. 
[2] R. Chauvin et al., work in progress

[3] a) J.S. Dewar, Bull. Soc. Chim. Fr. 1951, 18, C71-C79; b) J. Chatt, L. A. Duncanson, J. Chem. Soc. 1953, 2939-2947; c) J. Chatt, L. A. Duncanson, L. M. Venanzi, J. Chem. Soc. 1955, 4456-4460.

[4] T. J. Berlin, Chem. Phys. 1951, 19(2), 208-213.

[5] R. F. Bader, W. H. Henneker, P. E. Cade, J. Chem. Phys. 1967, 46, 3341-3363.

[6] T. Tal, J. Katriel, Theoret. Chim. Acta 1977, 46, 173-181.

[7] T. Koopmans, Physica 1934, 1, 104-113

[8] R. S. Mulliken, Phys. Rev. 1928, 32, 186-222.

[9 ] Y. Yamaguchi, R.B. Remington, J. F. Gaw, H. F. Schaefer III, Chem. Phys. 1994, 180, 5570.

[10] Y. Yamaguchi, R.B. Remington, J. F. Gaw, H. F. Schaefer III, G. Frenking, J. Chem. Phys. 1993, 98 (11), 8749-8760.

[11] Y. Yamaguchi, B. J. DeLeeuw, C. A. Richards, Jr., H. F. Schaefer III, G. Frenking, J. Am. Chem. Soc. 1994, 116, 11922-11930.

[12] A. Gobbi, Y. Yamaguchi, G. Frenking, H. F. Schaeffer III, Chem. Phys. Lett. 1995, 244, $27-$ 31.

[13] H.Y. Lee, S.P. Wang, T.C. Chang, Int. J. Quant. Chem. 2001, 81, 53-65

[14] F. W. Averill, G. S. Painter, Phys. Rev. B 1986, 34(4), 2088-2095.

[15] F. M. Bickelhaupt, J. K. Nagle, W. L. Klemm J. Phys. Chem. A 2008, 112, 2437-2446

[16] P. J. Robinson, A. N. Alexandrova, J. Phys. Chem. A 2015, 119, 12862-12867

[17] a) J. H. Choi, K. I. Oh, H. Lee, C. Lee, M. Cho, J. Chem. Phys. 2008, 128, 134506(1)134506(8); b) D. G. Gusev, Organometallics 2009, 28, 763-770; c) B. Vabre, Y. Canac, C. Lepetit, C. Duhayon, R. Chauvin, D. Zargarian, Chem. Eur. J. 2015, 21, 17403-17414; d) S. Lapointe, B. Vabre, D. Zargarian, Organometallics 2015, 34, 3520-3531.

[18] Gaussian 09, Revision A.01, M. J. Frisch et al. Gaussian, Inc., Wallingford CT, 2009.

[19] D. Cossart, C. Cossart-Magos, J. Mol. Spectrosc. 1991, 147 471-477

[20] D. Shi, W. Li, W. Xing, J. Sun, Z. Zhu, L. Liu, Comp. Theor. Chem. 2012, 980, 73-84.

[21] a) T. Yamabe, K. Hori, T. Minato, K. Fukui, Inorg. Chem. 1980, 19, 2154-2159 b) M. D. Fryzuk, S.A. Johnson, Coord. Chem. Rev. 2000, 200-202, 379-409.

[22] a) T. A. Albright, J. K. Burdett, M.-H. Whangbo, Orbital Interaction in Chemistry, John Wiley \& Sons, New York, 1984, pp 78-82; b). F. A. Cotton, G. Wilkinson, Advanced Inorganic Chemistry, 5th ed.; John Wiley \& Sons, New York, 1988 ; pp 58-64; c) R. H. Crabtree, The 
Organometallic Chemistry of the Transition Metals, 2nd ed.; John Wiley \& Sons: New York, 1994; pp 13-15.

[23] N. L. Ma, B. J. Smith, L. Radom, Chem. Phys. Lett. 1992, 197 (6), 573-580.

[24] A. J. Lupinetti, S. H. Strauss, G. Frenking, In Progress in Inorganic Chemistry, Vol. 49; Karlin, K. D., Ed.; Wiley, New York, 2001, pp. 1-49.

[25] U. Radius, F. M. Bickelhaupt, A. W. Ehlers, N. Goldberg, R. Hoffmann, Inorg. Chem. 1998, 37, 1080-1090.

[26] G. Frenking, C. Loschen, A. Krapp, S. Fau, S.H. Strauss, J. Comput. Chem. 2007, 28, 117126.

[27] A. J. Lupinetti, S. Fau, G. Frenking, S. H. Strauss, J. Phys. Chem. A 1997, 101, 9551-9559.

[28] R. F. W. Bader, A. D. Bandrauk, J. Chem. Phys. 1968, 49, 1653-1665.

[29] R. F. W. Bader, J. Keaveny, P. E. Cade, J. Chem. Phys., 1967, 47, 3381-3402.

[30] P. E. Cade, R. F. W. Bader, W. H. Henneker, I. Keaveny, J. Chem. Phys. 1969, 50, 53135333.

[31] C. E. Cotton, J. S. Francisco, W. Klemperer, J. Chem. Phys. 2013, 139, 014304.

[32] J. C. Owrutsky, C. S. Gudeman, C. C. Martner, L. M. Tack, N. H. Rosenbaum, R. Saykally, J. Chem. Phys. 1986, 84, 605-617.

[33] A. S. Goldman, K. Krogh-Jespersen, J. Am. Chem. Soc. 1996, 118, 12159-12166

[34] N. S. Hush, M. L. Williams, J. Mol. Struc. 1974, 50, 349-368.

[35] S. Liang, H. Wang, T. Deb, J. L. Petersen, G.T. Yee, M.P. Jensen, Inorg. Chem. 2012, 51, 12707-12719.

[36] W.E. Buschmann, J. S. Miller, Chem. Eur. J. 1998, 4, 1731-1737.

[37] C. Lepetit, V. Maraval, Y. Canac, R. Chauvin, Coord. Chem. Rev. 2016, 308 II, 59-75. 